\title{
The Risk Management Role of Accounting Conservatism for Operating Cash Flows
}

\author{
Gary C. Biddle ${ }^{*}$, Mary L. Z. Ma ${ }^{* *}$, Frank M. Song ${ }^{*}$ \\ Faculty of Business and Economics \\ University of Hong Kong \\ ${ }^{* *}$ Institute for Financial Accounting Studies \\ Xiamen University
}

May 20, 2012

\begin{abstract}
This study examines whether unconditional and conditional accounting conservatism (UC and $\mathrm{CC}$ ) serve risk management roles with respect to the downside properties of operating cash flows (OCF), and channels by which they operate. Our results reveal both UC and CC to be negatively associated with OCF downside risk measured by indicators of OCF falling below its expectations, OCF relative lower partial moments and OCF at risk. Tests of operative channels indicate that (1) UC and CC relate positively to cash holdings that reduce OCF downside risk and that (2) UC (CC) substitutes for (complements) corporate hedging in helping mitigate OCF downside risk. Further tests indicate that downside cash flow beta enhances the mitigating effects of UC and CC on OCF downside risk. These findings are robust to alternative measures and controls and lend support to accounting conservatism playing a risk management role with respect to OCF downside risk.
\end{abstract}

\section{JEL Classification: G1 M41 G32}

Keywords: accounting conservatism, risk management, downside risk, operating cash flows, hedging

Gary C. Biddle

Mary L. Z. Ma (Contact author)

Frank M. Song
Email: biddle@hku.hk

Email:mlizhi@yahoo.com

Email: fmsong@hku.hk
Telephone: (852) 2219-4388

Telephone: (86) 592-2182551

Telephone: (852) 2857-8507

This study derives from Mary L. Z. Ma's dissertation research at the University of Hong Kong. We appreciate comments and advice from Mark Defond, Jun Han, Sandy Hilton, Kai Wai Hui, David Koslowsky, Amy Lau, Xiaohong Liu, Xiumin Martin, Gurupdesh Pandher, Tanya Tang, Jing Wang, Yanyan Wang, Feng Wu, and from participants and discussants at the 2011 American Accounting Association annual meetings, at 2011 Canadian Academic Accounting Association annual meetings, at the 2011 AAA International Accounting Section Mid-Year meetings, at the 2010 Contemporary Accounting Review Symposium at Xiamen University, and at research seminars at the University of British Columbia at Okanagan, University of Hong Kong, Melbourne Business School, Nanyang Technological University, New York University and University of Tasmania. We thank the University of Hong Kong for providing financial support and Edgar-Online for allowing us to access their database for hedging usage data. 


\section{The Risk Management Role of Accounting Conservatism for Operating Cash Flows}

\section{Introduction}

Operating cash flow insufficiency and negative cash flow shocks are downside risks of primary concern to shareholders, debtholders, managers and other firm stakeholders. This study explicitly examines whether unconditional and conditional accounting conservatism (UC and CC) help mitigate operating cash flow (OCF) downside risk and their operative channels via two real risk management instruments - cash holdings and corporate hedging. Our results reveal both UC and $\mathrm{CC}$ to be negatively associated with subsequent $\mathrm{OCF}$ downside risk measured by indicators of OCF falling below expectations, OCF relative root lower partial moments (RRLPM) and OCF at risk, with cash flow beta a conditioning variable. Tests of operative channels reveal both UC and $\mathrm{CC}$ to complement cash holdings in mitigating OCF downside risk. UC (CC) is found to substitute for (complement) corporate hedging in mitigating OCF downside risk. This study is the first to provide direct evidence on the risk management role of accounting conservatism and on the joint use of accounting conservatism, cash holdings, and hedging in managing cash flow downside risk.

Accounting conservatism is defined as "a prudent reaction to risk and uncertainty to ensure that uncertainty and risks inherent in business situations are adequately considered," (Statement of Financial Accounting Concepts No. 2 (FASB 1980, p. 10)). Although this definition connotes a risk mitigation role, no prior study has explicitly examined relations between conservatism and OCF downside risk from a risk management perspective, with evidence regarding their potential relations limited though suggestive. For example, Francis and Martin (2010) and Luo and Watts (2011) argue that conservatism improves acquisition profitability by enhancing the monitoring of investments and helps alleviate capital underinvestment during financial crises by enhancing firms' borrowing capacity, respectively. This evidence suggests that conservatism holds the 
potential to mitigate OCF downside risk by improving capital investment efficiency. In contrast, Gigler, Kanodia, Sapra, and Venugopalan (2009) argue that conservatism induces covenant violations that may trigger inefficient liquidations of positive net present value projects, thus causing underinvestment and OCF shortfalls. Gao and Liang (2011) similarly argue that by weakening stock price information feedback, higher financial reporting quality (including conservative reporting) impedes investment efficiency and resource allocations, implying higher OCF downside risk. Therefore, it remains an open empirical question as to whether and how accounting conservatism plays a risk management role relevant to OCF downside risk.

Associations between accounting conservatism and OCF downside risk are of interest to investors, who have been documented previously to be loss-averse and attentive to downside risk (e.g., Roy 1952; Menezes, Geiss, and Tressler 1980; Tversky and Kahneman 1991; Koonce McAnally, and Mercer 2005a). In particular, Koonce et al. (2005a) find that investors place greater weight on loss probabilities and outcomes than on gains. Dutta and Radner (1999) argue that a top shareholder priority is to minimize downside risk to enhance firms' survival potentials; Minton and Schrand (1999) and Zhang (2008) argue that debtholder priories are to lower OCF risk and default risk that are major determinants of risk premia charged to borrowers. Risk management theories further argue that firms have incentives to hedge against negative cash flow shocks (Smith and Stulz 1985; Froot, Scharfstein, and Stein 1993) using instruments that include cash holdings, operating hedging, corporate hedging and lines of credit. Except for cash holdings, these instruments incur explicit costs and require business and financial expertise to execute (Disatnik, Duchin, and Schmidt 2012). In contrast, Pincus and Rajgopal (2002) argue that accounting-based risk management (e.g., earnings smoothing) involves less cost and expertise. If conservatism mitigates OCF downside risk, it would provide a low-cost risk management tool for managing OCF downside risk. 
Examining the risk management role of accounting conservatism also is of relevance to the ongoing debates regarding the benefits, costs and continuing role of accounting conservatism as a central tenet of financial accounting. The Financial Accounting Standard Board (FASB) and International Accounting Standards Board (IASB) removed conservatism from their Statement of Financial Accounting Concepts No. 8 in 2010 on the reasoning that it conflicts with neutrality. If this conceptual correspondence has the effect of reducing OCF downside risk, a reconsideration of conservatism's continuing role in financial accounting may be warranted.

UC and CC are predicted to directly mitigate OCF downside risk by enhancing investor monitoring, constraining earnings management, and by generating contracting benefits. By conveying to investors and other stakeholders timely information regarding firm performance and risk, UC and $\mathrm{CC}$ enhance the monitoring of firms' operations and risk management activities that reduce operational shocks (Ahmed and Duellman 2007; Ball, Bushman, and Vasvari 2008). This enhanced monitoring incentivizes managers with performance-based compensation to take attendant risk reducing actions (Francis and Xumin 2011). Accounting conservatism also discourages earnings overstatements and enhances the verifiability of accounting information (Watts and Zimmerman 1986; Gao 2011; Hui, Klasa, and Yeung 2012), thus enhancing the credibility of firms' financial reports and lowering bankruptcy risk (Biddle, Ma, and Song (BMS) 2012). This facilitates more favorable contracting terms (e.g., lower interest rates in debt contracting) and more stable trading relationships (e.g., longer-term sales contracts), thus helping alleviate underinvestment and reducing related negative OCF shocks and shortfalls.

Of equal interest is whether UC and CC influence OCF downside risk indirectly via risk mitigation instruments previously identified and how exogenous conditions influence relations between conservatism and OCF downside risk. In this study we examine two long-documented "real" risk management instruments, cash holdings and corporate hedging, as possible channels by which conservatism may influence OCF downside risk. Specifically, we hypothesize that 
both UC and CC reduce OCF downside risk via increasing cash holdings. In essence, these predictions follow from the reasoning that conservatism promotes precautionary cash savings as OCF uncertainty rises (Kirschenheiter and Ramakrishnan 2010) and increases cash from debt financings (Luo and Watts 2011). With more cash saved and borrowed, firms can better maintain operations and pursue growth opportunities, thus mitigating OCF negative shocks and shortfalls. We further hypothesize that UC (CC) will substitute for (complement) corporate hedging that has been found in prior studies to reduce OCF downside risk (Stulz 1996; Rawls and Smithson 1993). These predictions follow from the reasoning that UC is for many firms a commitment that pre-dates hedging whereas $\mathrm{CC}$ is conditional timely bad news reporting that would coincide with or post-date new bad-news-motivated hedging. As explained below, examining these indirect relations between accounting conservatism and OCF downside risk also holds the design advantage of controlling for a possible mechanical relation between conservatism and OCF downside risk arising from previously documented negative relations between accounting accruals and OCF (Basu 1997; Dechow 1994; Dechow, Kothari, and Watts 1998; Ball and Shivakumar 2005, 2006). ${ }^{1}$

Finally, we examine the exogenous influence on these relations of downside cash flow beta. $^{2}$ Our consideration of downside cash flow beta as an exogenous influence derives from prior findings that conservatism enhances borrowing ability during economic downturns (Luo and Watts 2011), which would thus reduce its potential to mitigate OCF downside risk.

To test these propositions and ensure robustness, we examine three OCF downside risk measures. Extending Stone (1973), Fishburn (1977) and Stein, Usher, LaGattuta, and Youngen (2001), OCF downside risk is measured by indicators for OCF dropping below its expectation,

\footnotetext{
${ }^{1}$ In brief, higher OCF increases negative accruals and accrual-based conservatism, and decreases negative OCF shocks and OCF downside risk, which can give rise to a potential negative mechanical relation between conservatism and OCF downside risk. Tests documenting indirect influences of accounting conservatism on OCF downside risk via other risk mitigation instruments do not reflect this effect.

${ }^{2}$ Disatnik et al. (2012) report that firms jointly use derivatives, cash holdings, and lines of credit to manage cash flow risk and that cash holdings are negatively associated derivative hedging.
} 
OCF RRLPM and OCF at risk (see Appendices A and B for details). For all three measures, R\&D and advertising expenses are added back to OCF to ensure that OCF downside risk reflects OCF shortfalls and insufficiency rather than the influences of growth potentials. Following BMS (2012), we measure UC using four measures: total accruals, the ranking of industry-adjusted book-to-market ratio, hidden reserves, and by a factor score from a principal components analysis (PCA) of these three measures. Extending BMS (2012), we similarly measure CC by four measures: accumulated non-operational accruals, an accrual-based $A R$ ratio, an accrualbased $C R$ ratio, and by a factor score from a PCA of these measures, where $A R$ and $C R$ ratios are adapted to exclude the confounding effects asymmetric timeliness of OCF following Tian, Collins, and Hribar (2009).

Our sample is comprised of 30,337 U.S. firm-year observations with available data for the OCF downside risk and conservatism measures for fiscal years 1992-2007. We employ logit models and Fama and MacBeth (1973) cross-sectional regression models to test the direct effects of UC and CC on OCF downside risk. Three-stage least squares (3SLS) regression models are used to examine the cash holdings channel and downside cash flow beta condition, together with an extended three-stage Heckman (1979) model for the hedging channel. These specifications control for endogeneity caused by reverse causality and common governance, risk and industry shocks.

Our empirical results indicate that both UC and CC directly mitigate subsequent OCF downside risk as hypothesized. Further analyses of channels and conditions indicate that (1) both UC and CC help enhance cash holdings that mitigate OCF downside risk; (2) UC (CC) substitutes for (complements) corporate hedging in mitigating OCF downside risk; (3) downside cash flow beta enhances the mitigating effects of UC and $\mathrm{CC}$ on OCF downside risk. As robustness checks, we examine whether our results are sensitive to alternate OCF expectation models, alternate deflators of OCF RRLPM and alternative conservatism measures, with 
qualitatively similar findings. We also consider the effects of monitoring by institutional shareholders, boards of directors and creditors, earnings smoothing, and alternate regression specifications, with results qualitatively unchanged. Altogether, our findings lend support to accounting conservatism serving a risk management role for OCF downside risk.

This study's findings contribute to several academic literatures. First, they extend the accounting conservatism literature by documenting associations between conservatism and OCF downside risk. Combining risk management theories and conservatism theory, this study contributes insights regarding the risk management role of accounting conservatism and provides initial evidence that $\mathrm{UC}$ and $\mathrm{CC}$ directly mitigate $\mathrm{OCF}$ downside risk. Our findings further document two specific channels (cash holdings and hedging) and an economic condition (downside cash flow beta) for the observed relations, which further illuminate the risk management role of accounting conservatism. In this context of the conservatism literature, these results both help to explain conservatism's longstanding use and standing as a tenant of financial accounting and will help inform deliberations determining its future.

Second, our findings are relevant to the risk management literature. In particular, Disatnik et al. (2012) investigate associations between derivative hedging, cash holdings, and lines of credit to manage cash flow risks while Gamba and Triantis (2011) analytically examine the joint usage of derivative hedging, cash holdings, and operational hedging. Barton (2001) and Pincus and Rajgopal (2002) focus on relations between accrual smoothing and derivative hedging. Complementing these studies, this study documents that both UC and CC complement cash holdings and that UC (CC) substitutes for (complements) derivative hedging in mitigating OCF downside risk, thus establishing conservatism as an accounting-based instrument that firms can employ in concert with other risk management tools. Our findings further contribute to this literature by documenting that hedging decreases whereas earnings smoothing increases OCF downside risk. 
Third, this study extends the downside risk literature by introducing three accountingbased OCF downside risk measures within the RRLPM and VaR frameworks that retain R\&D expenditures to better distinguish OCF shortfalls from growth effects and better control for OFC asymmetry that may influence prior measures including OCF volatility (Dechow et al. 1998; Luo, Ma, Wu 2012). This study also extends a growing literature relating accounting information quality and economic recessions (Balakrishnan 2009; Luo and Watts 2011; Beatty and Liao 2011). Balakrishnan (2009) argues that lower financial reporting quality magnifies and prolongs the negative consequences of economic downturns. Luo and Watts (2011) find conservatism to be associated with increased firm value during the 2008-2009 financial crisis consistent with enhanced borrowing capability and reduced under-investments; Beatty and Liao (2011) provide complementary evidence that conditional conservatism asymmetrically increases bank lending during economic recessions. Complementing these studies, this study provides evidence that the risk management effects of UC and CC strengthen during economic downturns.

Lastly, our findings have practical implications for economic policy-making and accounting standard-setting suggesting conservatism as a relatively low-cost accounting-based risk management tool that is especially effective during economic downturns when exogenous economic shocks are severe.

The remainder of this paper is organized as follows. Section 2 develops our hypotheses, Section 3 describes research methodologies, Section 4 reports empirical results and Section 5 concludes. Appendices A and B describe models used to estimate OCF downside risk.

\section{Hypothesis Development}

\subsection{The Risk Management Role of Accounting Conservatism}

Investors care about OCF downside risk. Beyond studies cited above documenting shareholders' and creditors' differing priorities for downside losses versus upside gains, Stulz (1996) argues explicitly that the purpose of risk management is to mitigate OCF downside 
volatility rather than overall volatility. Smith and Stulz (1985) and Froot et al. (1993) concur analytically that firms use derivative hedging to manage negative cash flow shocks and to minimize future financing and distress costs. Therefore, investors have natural incentives to monitor managers' operating decisions, investments and risk management activities to assure that firms survive negative OCF shocks. Bodnar, Hayt, and Marston (1998) report that investors are concerned about firms' hedging usage, and Koonce et al. (2005a, b) document that investors use accounting information to monitor managers' risk management activities.

Accounting conservatism has been argued to enhance investors' monitoring of firms' operations, investment, and risk management activities via the timely reporting of lower-tail realizations of earnings and assets (Ahmed and Duellman 2007; Ball et al. 2008). ${ }^{3}$ In turn, enhanced investor monitoring and feedbacks to managers incentivizes those with incentive compensation and concerns about career advancement to implement investment and risk management strategies that curtail OCF downside realizations. For example, timely loss recognitions and risk revelations stimulate the disciplining of under-performing managers in well-governed firms, thus motivating them to enhance operating efficiency, curb capital overinvestment and forego unprofitable acquisitions (Francis and Martin 2010). Conservatism also facilitates timely interventions and monitoring by debtholders after firms violate debt covenants, with the economic effect of improving investment and financial efficiency (Tan 2011). In both cases, heightened investment efficiency reduces negative OCF shocks and cash flow shortfalls. Despite a scarcity of evidence, timely risk information reporting via conservatism can likewise enhance the efficiency of risk management activities that ameliorate OCF shortfalls and mitigate negative OCF shocks.

\footnotetext{
${ }^{3}$ There is disagreement on this point in the literature. Gigler et al. (2009) argue that conservatism exercises less verification over bad earnings news and reports income-decreasing events on cost of downwardly biased estimation, thus reducing its information contents. Nevertheless, Gao (2011) demonstrates that in presence of managerial opportunism (e.g. earnings management), conservatism's role in counterbalancing earnings management rectifies for this downward bias, and thus conservatism still provides useful information that enhances monitoring.
} 
By understating earnings and net assets, accounting conservatism also directly reduces OCF downside risk by retaining more OCF within firms contracting with varied stakeholders and counterparties (managers and employees, revenue agencies, suppliers and customers, etc.). Firms' contracting terms are often based on accounting numbers. Lowering reported earnings and assets can thus lessen payouts to contracting parties even without changing contract terms in the presence of sufficient opacity, for example, for compensation (Watts 2003), interest (Ahmed, Billings, Morton, and Stanford-Harris 2002; Wittenberg-Moerman 2008), and taxes (Biddle 1980). These reduced cash outflows directly reduce OCF insufficiency and shortfalls, thereby diminishing OCF downside risk.

Conservatism has further been argued to constrain earnings overstatements and enhance the verifiability of accounting information (Watts and Zimmerman 1986; Gao 2011; Hui et al. 2012). This in turn enhances suppliers', customers', and other contracting parties' beliefs in the credibility of managers and firms' financial reporting, thus helping firms to win more favorable contracting and credit terms and longer-term contracts. These earnings management and contracting benefits of conservatism endow UC and CC with the potential to help mitigate negative cash flow shocks and minimize financing and distress costs. For example, if UC and $\mathrm{CC}$ mitigate customers' business risk by reducing earnings management and bankruptcy risk (BMS 2012), this increases firms' bargaining power and enhances long-term relations, thus reducing negative shocks from customers and product markets to firms' operations and OCF. In addition, UC and $\mathrm{CC}$ have been argued to reduce interest rates and enhance the availability of external financing for investments (Ahmed et al. 2002; Zhang 2008). Conservatism also tightens the wedge between internal and external costs of funds, thus relieving financial constraints and enabling firms to undertake more "marginal" investment projects (Luo and Watts 2012).

Collectively, these prior findings and inferences regarding the monitoring, managerial incentives, earnings management, and contracting effects for accounting conservatism suggest 
that both UC and CC should directly reduce OCF downside risk as reflected in hypothesis $\mathrm{H} 1$ :

H1: Unconditional and conditional conservatism directly reduce OCF downside risk.

\subsection{Cash Holdings, Corporate Hedging, and the Risk Management Role of Accounting Conservatism}

\section{Cash Holdings and the Risk Management Role of Accounting Conservatism}

We predict that UC and CC will reduce OCF downside risk indirectly by enhancing cash holdings, a well-recognized "real" risk management instrument. Accounting conservatism enhances cash holdings from external and internal sources, especially when under-investment and/or financial constraints are severe. Accounting conservatism enhances cash holdings from external financing by reducing interest expenses and boosting firms' borrowing capabilities, especially during economic downturns (Luo and Watts 2011). Conservatism also motivates precautionary cash savings when firms' future cash flows are risky (Kirschenheiter and Ramakrishnan 2010). Moreover, as suggested by risk management theories (Froot et al. 1993; Stulz 1996; Acharya et al. 2007), conservatism reduces the correlation between reported OCF and growth opportunities among growth firms by signaling OCF downside risk in a timely fashion, thus creating cash conservation incentives that alleviate under-investment and lessen financial constraints. With sufficient cash from internal and external sources, firms can better support their operations and attenuate under-investment, thus decreasing the probability of negative OCF realizations and OCF shortfalls. Corroborating this argument, Lins, Servaes, and Tufano (2010) document that firms hold excess cash mainly as a buffer against future cash shortfalls. Whereas larger cash holdings may exacerbate free cash flow related agency problems, such as cash wastage in firm operations and investments (Jensen 1986; Opler, Pinkowitz, Stulz, and Williamson 1999), thus leading to OCF shortfalls, this effect is ameliorated by findings that conservatism mitigates agency problems associated with increased cash holdings (Louis, Sun, and Urcan 2012). Combined, the above reasoning suggests that both UC and CC will reduce OCF downside risk by increasing cash holdings, as reflected in hypothesis $\mathrm{H} 2$ : 
H2: Unconditional and conditional conservatism indirectly reduce OCF downside risk via the cash holdings channel.

\section{Corporate Hedging and the Risk Management Role of Accounting Conservatism}

A second real risk management instrument examined in this study is corporate hedging. Specifically, we predict that UC and CC indirectly affect OCF downside risk by complementing or substituting for corporate hedging. Previous studies suggest that corporate hedging mitigates OCF downside risk; for instance, Smith and Stulz (1985) show analytically that hedging reduces bankruptcy risk by increasing income on the downside. Stulz (1996) further argues that the goal of corporate risk management is to eliminate lower-tail outcomes. Rawls and Smithson (1993) concur that chief financial officers selectively eliminate OCF downside risk rather than total risk. ${ }^{4}$ Campello, Lin, Ma, and Zou (2011) document that hedging reduces borrowing costs and relaxes debt covenants restricting investment, which hold the potential to reduce future OCF shortfalls.

Conservatism influences OCF downside risk by complementing or substituting for corporate hedging in several ways. On one hand, as noted, timely risk and loss revelations facilitate the ex post monitoring managers' risk mitigation activities by external stakeholders such as shareholders, debtholders, independent directors, auditors and regulators, which in turn incentivizes managers to initiate hedging for OCF negative shocks. This suggests a complementary relationship between conservatism and hedging. On the other hand, conservatism mitigates OCF shortfalls, predates and preempts hedging, and enhances cash holdings that substitute for hedging as documented by Disatnik et al. (2012). Thus, managers and other stakeholders may strategically employ low-cost accounting conservatism rather than more costly hedging instruments to mitigate OCF downside risk (Koonce et al. 2005a). ${ }^{5}$

\footnotetext{
${ }^{4}$ Some hedging instruments limit both OCF downside risk and upside potential. For example, a collar is an option that confines the range of possible positive or negative returns on an underlying indicator. Hedging instruments are often designed to decrease varied specific risk exposures which are ultimately reflected in OCF downside risk.

${ }^{5}$ Consistent with Disatnik et al. (2012), Knooce et al. (2005a) report that investors consider derivatives to be riskier than nonderivative financial instruments even when the underlying economic exposure is held constant.
} 
The reasoning suggests that relations between $\mathrm{UC}$ and $\mathrm{CC}$ and hedging may differ. In particular, UC is a major contributor to conservatism, is employed consistently over long periods, and is not bad news driven (Ryan 2006). Hence, UC is likely to predate and preempt arising hedging opportunities and dampen new hedging usage, especially productive hedging, and it enhances cash holdings that substitute for hedging. Hence, UC is more likely to serve as a costeffective substitute for new effective hedging. In contrast, $\mathrm{CC}$ is a smaller contributor to conservatism (Ryan 2006) and occurs sporadically. Hence, it precludes precautionary hedging to a lesser degree. Further, $\mathrm{CC}$ arises unexpectedly, conditional on bad news realizations, and conveys bad news in a timely manner regarding arising risk exposures, which helps motivate new hedging programs, encourage productive hedging and deter ineffective and speculative hedging. Thus, $\mathrm{CC}$ is more likely to serve as a cost-effective complement to new effective corporate hedging programs that reduce negative OCF shocks. Altogether, this reasoning implies that UC (CC) should substitute for (complement) corporate hedging and hedging effectiveness in mitigating OCF downside risk as reflected in hypothesis H3:

H3: Unconditional (conditional) conservatism substitutes for (complements) hedging usage and hedging effectiveness in mitigating OCF downside risk.

\subsection{Conjectures Regarding Downside Cash Flow Variance}

Modigliani and Miller (1958) suggest that in the presence of costly frictions during economic downturns, the effect of conservatism on OCF downside risk should be more salient. Economic downturns, especially financial crises, represent exogenous negative shocks that significantly weaken firms' funding ability and deteriorate under-investment problems. However, firms with higher conservatism possess enhanced borrowing capability (Luo and Watts 2011), so they can better maintain normal operations during economic downturns and survive OCF shortfalls. Moreover, during economic downturns when firms face more pressure to cut product prices to survive, greater conservatism exposes trading partners to lower bankruptcy risk (BMS 2012), which aids customer retention, thus reducing negative cash flow shocks. Negative 
economic shocks influence firm-level OCF downside risk via downside cash flow covariance. The above reasoning regarding the effects of negative economic shocks on firm-level OCF downside risk suggests that conditioning by downside cash flow covariance will enhance the mitigating effects of UC and CC on OCF downside risk.

\section{Data, Measures and Estimation Models}

\subsection{Data}

We examine a sample of 30,337 firm-year observations with available data listed on NYSE, AMEX and NASDAQ exchanges for fiscal years 1992 through $2007 .{ }^{6}$ Following Stein et al. (2001), we omit firm-year observations in the lower 5\% of the total asset distribution to mitigate the small denominator bias and delete industry-years with fewer than twenty observations to more accurately estimate OCF benchmark models. We require at least five years of continual data for calculating OCF downside risk, which induces a survival bias of some degree. We winsorize all variables at the top and bottom $1 \%$ of their distributions and exclude firms in the financial and utilities industries (firms with SIC codes 6000-6999 and 4900-4999 respectively).

To test the hedging channel, we hand-collect new hedging usage data for 445 hedging firms from 10-K annual reports in the Edgar-Online database for fiscal years 1995 to $2007 .{ }^{7}$ Following Zhang (2009) and Guay (1999), we focus on new hedging programs because the inherent business risk for firms with derivative positions is unobservable and thus renders it impossible to explain longitudinal results. Data for CEO incentives are obtained from ExecuComp.

\subsection{OCF Downside Risk Measures}

The traditional focus of risk management is OCF volatility rather than earnings volatility as it reflects the effects of risk-management activities on firms' real operations (Smith and Stulz

\footnotetext{
${ }^{6}$ This period is chosen to avoid possible bias caused by the financial crisis that can qualitatively change hypothesized relations and to enhance the availability of cash flow statement data. FASB Statement of Financial Accounting Standards (SFAS) No. 95 required firms to report cash flow statements for fiscal years ending after 15 July 1988; Lorek and Willinger (1996) and Hribar and Collins (2002) document measurement errors in cash flow estimates based on prior data. Because the OCF measures used in this study require lagged observations, 1989 data allows us to measure OCF beginning in 1992 .

${ }^{7}$ The 10-K annual reports of U.S. listed firms in the Edgar-Online database are available for fiscal years 1994 to 2007.
} 
1985; Froot et al. 1993; Zhang 2009). ${ }^{8}$ Moreover, the current downside properties of OFC are of most interest to investors as documented above (Stulz 1996 and Koonce et al. 2005a) rather than earnings downside risk that more reflects future OCF downside risk. Detailed below are the three measures used in this study for current OCF downside risk: $D O C F$, which is an indicator that OCF drops below its expected level; Rlpm_OCF, the RRLPM of OCF, and CFaR, OCF atrisk.

\section{OCF Downside Risk Measures within the RRLPM Framework}

OCF downside risk measures DOCF and Rlpm_OCF belong to the RRLPM framework developed based on the lower partial moment (LPM) concept. LPM includes only the downside distribution of a variable relative to a reference level in moment calculation (Stone 1973; Fishburn 1977). For OCF with possible value realization $\gamma$, the continuous case of LPM of OCF for a given firm $i, L P M_{\alpha}(\tau: i)$, is expressed by the following cumulative distribution function:

$$
\operatorname{LPM}_{\alpha}(\tau: i)=\int_{-\infty}^{\tau}\left|\tau-\gamma_{i}\right|^{\alpha} f\left(\gamma_{i}\right) d \gamma_{i}, \alpha \geq 0
$$

where $\tau$ is the OCF target level, and $f\left(\gamma_{i}\right)$ is the probability density function for firm $i$ 's OCF. $\alpha$ is a moment indicator that reflects the relative importance of the magnitude that OCF deviates below its target level. For $\alpha=0$, the magnitude does not matter and $\operatorname{LPM}_{\alpha}(\tau: i)$ collapses to an indicator of below-target OCF. For $\alpha=1$ and $\alpha=2, L P M_{\alpha}(\tau: i)$ is consistent with below-target shortfall and semi-variance, but not with a mere shortfall and semi-variance since even for symmetric distributions, if the target OCF $\tau$ deviates from the sample mean, OCF LPM will still differ from OCF shortfalls and semi-variance. The discrete case for OCF LPM for a given firm $i$ when $\alpha=2$ is expressed as:

$$
\operatorname{LPM}_{2}(\tau: i)=\left(\frac{1}{N}\right) \sum_{\gamma_{i}<\tau}^{\tau}\left(\tau-\gamma_{i}\right)^{2}
$$

where $N$ is the number of observations in the sample. Root lower partial moment RLPM is the

\footnotetext{
${ }^{8}$ In addition, changes in earnings volatility also capture effects of accounting treatments (Zhang 2009), which by construction introduces mechanical relations between conservatism and its risk management consequence on OCF downside risk.
} 
root of LPM and is linearly homogeneous of degree one such that changes in $\tau$ and in LPM are proportional. The discretionary case of OCF RLPM for firm $i$ when $\alpha=2$ is expressed as:

$$
\operatorname{RLPM}_{2}(\tau: i)=\operatorname{LPM}_{2}(\tau: i)^{1 / 2}=\left[\left(\frac{1}{N}\right) \sum_{\gamma_{i}<\tau}^{\tau}\left(\tau-\gamma_{i}\right)^{2}\right]^{1 / 2}
$$

Following the spirit of RLPM, we also estimate a root upper partial moment of OCF RUPM that captures OCF upside potentials and the probability that OCF deviates above its expected level. To the extent that higher RUPM usually accompanies higher RLPM, we construct RRLPM, a relative RLPM measure that deflates RLPM by RUPM to control for firmlevel differences in upside potentials and thus better compares OCF downside risk across firms. Applying an logarithm transformation we get the following RRLPM of OCF definition:

RRLPM of OCF Rlpm_OCF. Rlpm_OCF refers to the ranked natural logarithm of the ratio of one plus the OCF RLPM over one plus the OCF RUPM, with both RLPM and RUPM estimated over a three-year horizon covering the current and previous two years:

$$
R l p m_{-} O C F_{i t}=\log \left[\left(1+\mathrm{RLPM}_{2}\left(O C F_{i t}\right) /\left(1+\mathrm{RUPM}_{2}\left(O C F_{i t}\right)\right]\right.\right.
$$

where $R L P M_{2}\left(O C F_{i t}\right)=\left[(1 / 3) \Sigma\left(\left(\dot{\varepsilon}_{\mathrm{it}} * \mathrm{I}_{\mathrm{it} \leq 0}\right)^{2}\right]^{1 / 2}\right.$, and $R U P M_{2}\left(O C F_{i t}\right)=\left[(1 / 3) \Sigma\left(\left(\dot{\varepsilon}_{\mathrm{it}} * \mathrm{I} \dot{\varepsilon}_{\mathrm{it} \geq 0)}\right)\right)^{2}\right]^{1 / 2}$, representing the OCF RLPM and RUPM respectively. I $\varepsilon_{\text {it } \leq 0}$ is an indicator that equals one if $\dot{\varepsilon}_{\mathrm{it}}<0$ and zero otherwise, wherein $\dot{\varepsilon}_{\text {it }}$ is the residual from an OCF expectation model as shown below:

$$
\begin{aligned}
O C F_{i t}= & \beta_{0}+\beta_{1} O C F_{i t-1}+\beta_{2} O C F_{i t-2}+\beta_{3} O C F_{i t-3}+\beta_{4} S A L E_{i t-1}+\beta_{5} S I Z E_{i t-1} \\
& +\beta_{6} L E V E R A G E_{i t-1}+\beta_{7} S T D \_O C F_{i t-1}+\text { Year_Dummies }+\varepsilon_{i t}
\end{aligned}
$$

where $O C F$ is the ratio of annual OCF to total assets. Concurrently expensed R\&D and adverting expenditures are added back to OCF so that Rlpm_OCF as calculated is free of the effects of growth potentials and reflects only OCF shortfalls. Model (5) incorporates OCF level and volatility (Minton, Schrand, and Walther 2002) along with other economic determinants of OCF such as firms size, sales (Dechow 1994; Dechow et al. 1998), and leverage. The rationale for these determinants and other model details is described in Appendix A.

We define the special case for RRLPM of OCF with zero moment $(\alpha=0)$ as below: 
Indicator of OCF Deviating below Expectation DOCF. DOCF is a dummy variable indicating that OCF falls below its expected level, and is equal to one when the residual from equation (5) $\dot{\varepsilon}_{\mathrm{it}}<0$, and zero otherwise.

\section{OCF Downside Risk Measures within the VaR Framework}

OCF at Risk CFaR. CFaR falls within the value at-risk $(\mathrm{VaR})$ framework and refers to the ranked ratio of the worst case of quarterly OCF at a $1 \%$ confidence level estimated from its probability distribution to the expected OCF estimated from a quarterly estimation model: ${ }^{9}$

$$
\begin{aligned}
\text { OCF } Q_{t}= & \beta_{0}+\beta_{1} O C F Q_{t-1}+\beta_{2} O C F Q_{t-2}+\beta_{3} O C F Q_{t-3}+\beta_{4} O C F Q_{t-4}+\beta_{5} O C F Q_{t-5} \\
& +\gamma_{1} Q_{1}+\gamma_{2} Q_{2}+\gamma_{3} Q_{3}+\varepsilon_{t}
\end{aligned}
$$

where $O C F Q$ is the ratio of quarterly OCF to total assets, with quarterly OCF adjusted for R\&D and adverting expenditures to ensure that the estimated $C F a R$ is free from the effects of related growth potentials and hence only captures OCF insufficiency. Extending Stein et al. (2001), we employ a comparables approach to calculate $C F a R$ over a rolling window of seventeen fiscal quarters with estimation details in Appendix B. ${ }^{10}$

Comparing the OCF downside risk measures, DOCF is a dummy variable, simplest but insensitive to the magnitude of OCF downside risk; $C F a R$ considers only the extreme loss case and is most appropriate for crisis analyses; Rlpm_OCF considers all loss levels but is computationally more complex.

\subsection{Accounting Conservatism Measures}

Following BMS (2012), this study considers four UC measures: UC_ACC (total accrual adapted from Ahmed et al. 2002), UC_BM (the ranked industry-adjusted BM ratio), UC_RES hidden reserve (Penman and Zhang 2002), and UC_PCA, a factor score generated from a PCA of the above three UC measures and is used as the primary UC measure. Extending BMS (2012),

\footnotetext{
${ }^{9} \mathrm{CFaR}$ is similar to $\mathrm{VaR}$, the potential loss in value of a risky asset or portfolio over a defined period for a given confidence interval. However, unlike $\mathrm{VaR}, \mathrm{CFaR}$ focuses on the overall OCF effects of all types of risk exposures rather than on the value effect of only risk exposures of specific financial assets.

${ }^{10}$ The comparables approach is a nonparametric method that sorts firms with similar risk features into pools of comparable peer firm-quarters to construct large samples of negative OCF shocks. Compared with the technique using only one company's data, the comparables approach uses data of both a firm and its comparables and facilitates estimating over tail probabilities.
} 
this study similarly employs four CC measures: $C C \_A C M$ (accumulated non-operating accruals), $C C_{-} A R A$ (an extension of $C C_{-} A R$ in BMS 2012), $C C_{-} C R A$ (an extension of the $C C_{-} C R$ in BMS 2012), and CC_PCA, a factor score generated from a PCA of the above three CC measures and is used as the primary $\mathrm{UC}$ measure. $C C_{-} A R A$ and $C C_{-} C R A$ exclude asymmetric OCF timeliness from $C_{-} A R$ and $C C_{-} C R$, respectively, because it is irrelevant to conservatism and overstates the Basu- and other market-based CC measures (Tian et al. 2009). ${ }^{11}$

CC_ARA. CC_ARA is the ranked ratio of the sum of the C Score and the G Score to the G Score estimated from an extended Khan and Watts (2009) model that replaces earnings with accruals to retain only asymmetric accrual timeliness. ${ }^{12}$

CC_CRA. $C C_{-} C R A$ is the ranked ratio of current accrual shocks to total accrual news multiplied by -1 for good accrual news. It extends the $C C_{-} C R$ in BMS (2012) by focusing on only the asymmetric timeliness of bad relative to good accrual news. ${ }^{13}$

\footnotetext{
${ }^{11}$ In particular, asymmetric OCF timeliness could otherwise inflate $C C \_A R$ and $C C_{-} C R$ and increase OCF downside risk at the same time, leading to a spurious positive relation between $C C_{-} A R$ and $C C_{-} C R$ and OCF downside risk, which weakens the testing power of our empirical analysis for the hypothesized negative relation between them. Therefore, it is important to net out asymmetric cash flow timeliness from both $C C_{-} A R$ and $C C_{-} C R$.

12 We estimate the following model for fiscal years 1990 to 2007 :

$A C C_{i t}=b_{1}+b_{2} D R_{i t}+R_{i t} *\left(m_{1}+m_{2} S_{i z e}+m_{3} M / B_{i t}+m_{4} L E V_{i t}\right)+D R_{i t} * R_{i t}\left(l_{1}+l_{2} S_{i z} e_{i t}+l_{3} M / B_{i t}+l_{4} L E V_{i t}\right)$

Then GScore_ACC $C_{i t}=m_{1}+m_{2}$ Size $_{i t}+m_{3} M / B_{i t}+m_{4} L E V_{i t}=-1.89539+$ Size $_{i t} * 0.5239-M / B_{i t} * 0.0367-L E V_{i t} * 1.7393$

$C_{-}$Score_ACC $C_{i t}=l_{1}+l_{2}$ Size $_{i t}+l_{3} M / B_{i t}+l_{4} L E V_{i t}=3.3696-$ Size $^{*} 0.9200+M / B_{i t} * 0.0456+L E V_{i t} * 2.75340$

where the CScore_ACC (GScore_ACC) score refers to C (G) score that measures the timeliness of bad (good) accruals news.

${ }^{13}$ Specifically, we replace earnings with accruals $(a c c)$ and OCF $(c f)$ in the return decomposition model:$$
r_{t}-E_{t-1}\left(r_{t}\right)=\Delta E_{t} \sum_{j=1}^{\infty} \rho^{j}\left(a c c_{t+j}\right)+\Delta E_{t} \sum_{j=1}^{\infty} \rho^{j}\left(c f_{t+j}-i_{t+j}\right)-\Delta E_{t} \sum_{j=1}^{\infty} \rho^{j} r_{t+j}=N a c c+N c f-N r
$$

where $\Delta$ denotes first differencing; $E_{t}$ is an expectation operator; $\Delta E_{t-1}=E_{t}()-.E_{t-1}(.) ; \rho$ is a constant discount rate term; $i_{t}=$ $\log \left(1+r f_{t}\right) ; r f_{t}$ is the risk free rate in period $t ; r_{t}=\log \left(1+r e t_{t}\right)-i_{t} ;$ ret $_{t}$ is the equity return (cum dividend) in period $t ; a c c_{t}=$ $\log \left(1+\left(E_{t}-O C F_{t}\right) / B V_{t}\right) ; E_{t}$ is earnings; $O C F_{t}$ is OCF; and $c f_{t}=\log \left(1+O C F_{t} / B V_{t}\right)$. Nacc is accrual news defined as $\Delta E_{t}$ $\sum_{j=1}^{\infty} \rho^{j}\left(a c c_{t+j}\right)$, Ncf is cash flow news defined as $\Delta E_{t} \sum_{j=1}^{\infty} \rho^{j}\left(c f_{t+j}-i_{t+j}\right)$ and $N r$ is discount rate news defined as $\Delta E_{t}$ $\sum_{j=1}^{\infty} \rho^{j} r_{t+j}$. Following Callen, Livnat, and Segal (2006), we use $r_{t}, a c c_{t}, c f_{t}$ and $b m_{t}$ as the state variables in a VAR (1) model to
} estimate Nacc:

$$
\begin{gathered}
r_{t}=\alpha_{0}+\alpha_{1} r_{t-1}+\alpha_{2} a c c_{t-1}+\alpha_{3} c f_{t-1}+\alpha_{4} b m_{t-1}+\eta_{1 t} \\
a c c_{t}=\lambda_{0}+\lambda_{1} r_{t-1}+\lambda_{2} a c c_{t-1}+\lambda_{3} c f_{t-1}+\lambda_{4} b m_{t-1}+\eta_{2 t} \\
c f_{t}=\beta_{0}+\beta_{1} r_{t-1}+\beta_{2} a c c_{t-1}+\beta_{3} c f_{t-1}+\beta_{4} b m_{t-1}+\eta_{3 t} \\
b m_{t}=\phi_{0}+\phi_{1} r_{t-1}+\phi_{2} a c c_{t-1}+\phi_{3} c f_{t-1}+\phi_{4} b m_{t-1}+\eta_{4 t} \\
\left.N a c c{ }_{t}=\Delta E_{t} \sum_{j=1}^{\infty} \rho^{j} a c c_{t+j}=r_{t}-E_{t-1}\left(r_{t}\right)+N r_{t}-N c f_{t}=\rho e_{2}^{\prime}(\mathrm{I}-\rho \mathrm{A})\right)^{-1} \eta_{t}
\end{gathered}
$$

where $\eta_{t}$ refers to the vector $\left(\eta_{1 t}, \eta_{2 t}, \eta_{3 t} \eta_{4 t}\right)^{\prime}$, I is the identity matrix and $\mathrm{A}$ is the parameter matrix. We then calculate $C C_{-} C R A=$ $\eta_{2 t} / \mathrm{Nacc}_{t}$ if $\mathrm{NaCc}_{t}<0$ and CC_ACCA $A_{t}=-\eta_{2 t} / \mathrm{Nacc}_{t}$ if $\mathrm{Nacc}_{t}>0$. 


\subsection{Estimation Methodology and Models}

\subsubsection{Direct Effects of UC and CC on OCF Downside Risk}

This study uses the following model (7) to test H1 regarding the direct effects of UC and

CC on subsequent OCF downside risk, with $\mathrm{H} 1$ predicting $\gamma_{1}<0$ :

$$
\text { DR_OCF } F_{i t}=\gamma_{0}+\gamma_{1} \text { CON }_{i t-1}+\text { Controls }_{i t}+\varepsilon_{i t}
$$

where $D R \_O C F$ refers to $D O C F, R l p m \_O C F$ or $C F a R$, and $C O N$ refers to UC proxies $U C \_P C A$, UC_ACC, UC_BM, UC_RES, and CC metrics CC_PCA, CC_ACM, CC_ARA and CC_CRA.

Model (7) takes the form of logit model with $D O C F$ as dependent variable and Fama and MacBeth (1973) model with Rlpm_OCF or CFaR as dependent variable. The control variables Controls $_{i t}$ include previously identified determinants of OCF downside risk. ${ }^{14}$

\subsubsection{Three-stage Least Square (3SLS) Model for Cash Holdings Channel}

We employ the following 3 SLS model to test $\mathrm{H} 2$ regarding the cash holdings channel. The first-stage OLS model (equation (8)) regresses UC and CC on cash holdings, their common risk, governance and industry determinants, to control for endogeneity between UC and CC and cash holdings caused by their reverse causality, plus common risk, governance, industry and sector factors. The second-stage (equation (9)) OLS model regresses cash holdings on the residuals of $\mathrm{UC}$ and $\mathrm{CC}$ estimated from the first-stage, $U C_{-} R$ and $C_{-} R$, and other determinants of cash holdings. ${ }^{15}$ The third-stage OLS model (equation (10)) regress future OCF downside risk $D R \_O C F$ against residuals of cash holdings from the second-stage $C H \_R$ and other determinants

\footnotetext{
${ }^{14}$ In particular, these control variables include cash holdings $C A S H$, change in cash holdings $\triangle C A S H$, capital investment intensity Invest_Capx, R\&D investment intensity Invest_RD, organizational slack SLACK, human resource slack SLACK_EMP, firm size $S I Z E$, return on total assets $R O A$, financial leverage Leverage, operating options $O O$, past return volatility Sigma, CEO effort-taking incentives $C E O \_$Delta and CEO risk-taking incentives CEO_Vega. There is no consensus regarding the sources of OCF downside risk in the literature. Zhang (2009) suggests that the determinants of OCF volatility include the intensity of the plant, property, plant and equipment (PPE hereafter) $(-)$, firm size $(-)$, growth opportunities $(+)$, leverage $(+)$, return volatility $(+)$, CEO risk-aversion incentives (-) and CEO risk-taking incentives (+). Similarly, Ang, Chen, and Xing (2006) document that firms with high ROEs, small firm size, high asset-growth, low book-to-market ratio, high return volatility, high past downside betas and past winners have a high downside beta (Dbeta). Other studies show that past organizational slackness (Miller and Reuler 1996) and operating options proxied by capitalized PPE assets (Driouchi and Bennett 2010) reduce downside risk. Dummies for Fama and French (1997) industry classifications Ind and for fiscal years Year are included to capture fixed industry and year effects, respectively.

${ }^{15}$ Controls 1 in equation (9) include $\triangle$ Cash, Dissue, DIV, Leverage, Loss, NWC, OO, ROA, Sigma, Size, Slack, Slack_emp, CEO_Delta and CEO_Vega, and year and industry dummies, which are common determinants of cash holdings documented in the literature (Bates, Kathleen, and Stulz 2009; Opler et al. 1999). Controls2 in equation (10) are the same as control variables used in Model (7).
} 
of Rlpm_OCF.

$$
\begin{aligned}
& \operatorname{CON}_{i t}=\alpha_{0}+\alpha_{1} \operatorname{CON}_{i t-1}+\alpha_{2} \text { Cash }_{i t-1}+\alpha_{3} \text { ROA }_{i t-1}+\alpha_{4} \text { Size }_{i t-1} \\
& +\alpha_{5} \text { Leverage }_{i t-1}+\Sigma b_{m} \text { Ind }_{m}+\Sigma b_{n} \text { Year }_{n}+v_{i t-1} \\
& \mathrm{CH}_{i t}=b_{0}+b_{1} U C_{-} P C A_{-} R_{i t-1}+b_{2} C C_{-} P C A_{-} R_{i t-1}+\text { Controls }_{i t}+\varepsilon_{i t} \text {, } \\
& R l p m \_O C F_{i t}=\gamma_{0}+\gamma_{1} C h \_R_{i t-1} * U C \_P C A \_R_{i t-1}+\gamma_{2} C h \_R_{i t-1} * C C \_P C A \_R_{i t-1} \\
& +\gamma_{3} U C_{-} P C A_{-} R_{i t-1}+\bar{\gamma}_{4} C C_{-} P C A_{-} R_{i t-1}+\gamma_{5} C H_{-} R_{i t-1}+\text { Controls }_{i t-1}+\mu_{i t}
\end{aligned}
$$

where CON $=U C_{-} P C A$ or $C C_{-} P C A$, and $\mathrm{CH}=$ Cash. $\mathrm{H} 2$ predicts $b_{1}, b_{2}>0$ and $\gamma_{5}<0$ for the effects of both UC and CC via the cash holdings channel. Following Baron and Kenny (1986), the mediating effect of the cash holdings channel refers to its effect on OCF downside risk as stimulated by $\mathrm{UC}$ and $\mathrm{CC}$, and it is equal to the product of $\beta_{1}$ and $\gamma_{2}$.

\subsubsection{Extended Heckman (1979) Model for the Hedging Channel}

We use the extended three-stage Heckman (1979) model below to test H3 regarding the hedging channel, augmenting the classical Heckman model by: (1) adding a one-stage OLS regression (equation (11)) ahead of the previous first-stage probit model to control for endogeniety between conservatism and hedging due to their reverse causality and common risk, governance, industry and sector factors; (2) employing a difference-in-differences specification in the last stage OLS regression (equation (13)) because examining only firms that initiate hedging programs (treatment firms) could yield biased results when there are other changes coincident to the initiation of new hedging programs. ${ }^{16}$ Specifically, equation (11) regresses both $U C_{-} P C A$ and $C C_{-} P C A$ on the hedging indicator, risk and governance factors common to both conservatism and hedging. Equation (12) is a probit model that regresses a firm's propensity to be a hedger against residuals from equation (11), $U C_{-} P C A_{-} R$ and $C_{-} P C A_{-} R$, and other determinants to examine the effects of UC and CC on firms' hedging decision. ${ }^{17}$ Equation (13) is

\footnotetext{
${ }^{16}$ We use firms that have never initiated any hedging programs as control firms. In our specification, the first differencing level is the change in $\mathrm{UC}$ or $\mathrm{CC}$ before and after the initiation of a hedging program for each treatment firm. The second differencing level is the change in UC or CC between control and treatment firms, with the aim to remove the impact of other changes concurrent with the initiation of new hedging program from the first-level differencing. The implicit assumption is that other changes affect both treatment and control firms similarly.

${ }^{17}$ Hedging determinants include firm size SIZE $(+)$, leverage ratio LEVERAGE $(+)$, profitability ROA (+), growth opportunities Invest_RD (+), underinvestment LEVERAGE*Invest_RD (+), interest burden INT_BD (+), tax convexity NOL (+), return volatility SIGMA (-), information asymmetry $B A S \overline{(-)}$, CEO effort-taking and risk-taking incentives CEO_Delta (-) and CEO_Vega $(+)$ and IND and Year dummies. They are common determinants of derivative hedging well-documented in the risk
} 
a difference-in-differences OLS model that regresses future $R l p m \_O C F$ against $U C \_P C A \_R$ and CC_PCA_R, hedging indicator Hedger, the inverse Mills ratio Mills, and other controls. H3 predicts that $b_{1}, b_{2} \neq 0$ and $\gamma_{1}, \gamma_{2} \neq 0$ in equations (12) and (13) respectively.

$$
\begin{aligned}
& C O N_{i t}=\alpha_{0}+\alpha_{1} C O N_{i t-1}+\alpha_{2} R l p m_{-} O C F_{i t-1}+\alpha_{3} R O A_{i t-1}+\alpha_{4} \text { Size }_{i t-1} \\
& +\alpha_{5} \text { Leverage }_{i t-1}+\alpha_{6} C E O{ }_{-} \text {Delta }_{i t-1}+\alpha_{7} C E O \_V e g a_{i t-1} \\
& +b_{9} \text { Hedger }_{i t}+\Sigma b_{n} \text { Ind }_{n}+\Sigma b_{o} \text { Year }_{o}+v_{i t} \\
& \text { Hedger }_{i t} \quad=b_{0}+b_{1} U C_{-} P C A_{-} R_{i t-1}+b_{2} C C_{-} P C A_{-} R_{i t-1}+\text { Controls }_{i t-1}+\varepsilon_{i t} \\
& \text { Rlpm_OCF } F_{i t}=\gamma_{0}+\gamma_{1} \text { Post }_{i t} * \text { Hedger }_{i t}+\gamma_{2} \text { Hedger }_{i t} * U C_{-} \text {PCA_R } R_{\text {it- }-1} * \text { Post }_{i t} \\
& +\gamma_{3} \text {Hedger }_{i t} * \mathrm{CC}_{-} P C A_{-} R_{i t-1} * \text { Post }_{i t}+\gamma_{4} U C_{-} \text {PCA_R } R_{i t-1} \\
& +\gamma_{5} \text { CC_PCA_R } R_{i t-1}+\gamma_{6}{ }_{P} \text { ost }_{i t}+\gamma_{7} \text { Mills }_{i t-1}+{ }_{\text {Controls }} 4_{i t}+\mu_{i t}
\end{aligned}
$$

\section{Empirical Results}

\subsection{Descriptive Analysis}

Table 1 reports summary statistics for all variables and Table 2 presents Pearson and Spearman correlations among the major testing variables in its upper and lower triangles, respectively. The mean and median of Rlpm_OCF in Table 1 are 0.0936 and 0.0360 , respectively, which are larger than the corresponding figures of -0.020 and 0.021 reported in Luo et al. (2012). This likely attributable to our inclusion of R\&D and advertising expenses in OCF when calculating Rlpm_OCF to factor out growth potentials. Table 2 indicates strong contemporaneous partial correlations among the testing variables. Specifically, the three $O C F$ downside risk measures $\left(D O C F, R l p m \_O C F, C F a R\right)$ are significantly negatively correlated with all UC (UC_PCA,UC_ACC,UC_BM) and CC (CC_PCA,CC_ACM, CC_ARA, CC_CRA) metrics, except that $C F a R$ exhibits a positive Spearman (Pearson) correlation with $C C_{-} A R A$ $\left(C C \_C R A\right)$. These results provide initial evidence that both $\mathrm{UC}$ and $\mathrm{CC}$ are negatively associated with OCF downside risk, consistent with hypothesis H1. The Pearson and Spearman correlations

\footnotetext{
management literature (Smith and Stulz 1985; Graham and Smith 1999; Barton 2001; Zhang 2009). Specifically, SIZE controls for the scale of economy in hedging. LEVERAGE and ROA proxy for incentives to use derivatives to reduce expected costs of financial distress and to facilitate external financing, and they are positively associated with increased incentives to use derivatives to prevent drops in profitability when firm performance is good. LEVERAGE*Invest_RD and Invest_RD, proxy for growth opportunities and incentives to use hedging to mitigate underinvestment problems, respectively, and both are expected to be positively related to hedging. $I N T B B D$ captures hedging incentives from increased interest burden, $N O L$ captures taxation convexity incentives for hedging, and both are expected to be positively associated with hedging. CEO_Vega and CEO_Delta capture managerial risk-aversion and risk-taking incentives for hedging, respectively, with $C E O \_V e g a\left(C E O \_D e l t a\right)$ predicted to be positively (negatively) associated with hedging (Guay 1999; Zhang 2009). BAS captures the information asymmetry incentives and is expected to be negatively associated with hedging.
} 
of DOCF and Rlpm_OCF with cash holdings Cash are consistently significantly negative, whereas those of CFaR with Cash are consistently positive. The Pearson and Spearman correlations of all OCF downside risk measures with the hedging indicators Hedger are consistently negative, suggesting that corporate hedging helps reduce OCF downside risk.

\subsection{Unconditional and Conditional Conservatism and OCF Downside Risk}

Tables 3 to 5 report testing results for $\mathrm{H} 1$ regarding the direct effects of $\mathrm{UC}$ and $\mathrm{CC}$ on OCF downside risk. Table 3 presents results for logit model regressions of DOCF on lagged UC and $\mathrm{CC}$ and other control variables. In model 1 , both UC and $\mathrm{CC}$ measures $U C_{-} P C A_{i t-1}$ and $C C_{-} P C A_{i t-1}$ are significantly negatively associated with $D O C F_{i t}$, with coefficients ( $t$-statistics) of $-0.4341(-4.67)$ and $-0.1436(-2.48)$, respectively. Models 2 to 7 report results for other UC measures $U C_{-} A C C_{i t-1}, U C_{-} B M_{i t-1}$ and $U C_{-} R E S_{i t-1}$ simultaneously controlling for $C C_{-} P C A_{i t-1}$, and results for other $\mathrm{CC}$ measures $C C_{-} A M_{i t-1}, C C_{-} A R A_{i t-1}$, and $C C_{-} C R A_{i t-1}$ simultaneously controlling for $U C_{-} P C A_{i t-1}$. UC measures $U C_{-} B M_{i t-1}$ and $U C_{-} R E S_{i t-1}$ are significantly negatively associated with $D O C F_{i t}$, except that $U C_{-} A C C_{i t-1}$ is insignificantly negatively associated with $D O C F_{i t}$. All CC measures $C C_{-} A M_{i t-1}, C C_{-} A R A_{i t-1}$, and $C C_{-} C R A_{i t-1}$ are significantly negatively associated with $D O C F_{i t}{ }^{18}$ These results strongly support hypothesis $\mathrm{H} 1$ by indicating that UC and $C C$ mitigate subsequent $O C F$ downside risk proxied by $D O C F .^{19}$

Table 4 reports results for the Fama-Macbeth regressions of the subsequent $R l p m \_O C F_{i t}$ on UC and CC and other control variables. Model 1 shows both $U C_{-} P C A_{i t-1}$ and $C C_{-} P C A_{i t-1}$ to be strongly negatively associated with $R l p m_{-} O C F_{i t}$, with coefficients ( $t$-statistics) of -0.0137 (-

\footnotetext{
${ }^{18}$ A possible concern is that these results are influenced by R\&D and marketing expenditures that increase hidden reserves, UC and OCF downside risk, thus creating a spurious positive relation between conservatism and OCF downside risk, particularly since R\&D is often financed in stages (Bergemann, Hege, and Peng 2011). We address this possibility by adjusting all OCF downside risk measures for R\&D expenditures as noted above. Further, even if this positive relation exists, it runs counter to the hypothesized and observed negative relation between conservatism and OCF downside risk, thus implying that if present, the true relation is more strongly negative than observed.

${ }^{19}$ The estimated coefficients for control variables are generally consistent with predictions. For example, the coefficient for cash holdings Cash is significantly negative in all models. The coefficients for capital investment Invest_CAPX and R\&D investment Invest $R D$ are significantly negative, consistent with the notion that optimal investment increases future OCF and thus reduces the probability that a firm's OCF fall below its expected level. Similarly, the coefficients on $O O, R O A, L O S S$, SIGMA, and CEO_Delta are significantly negative and Leverage, Size, and human resources slackness SLACK_emp increase with DOCF as predicted.
} 
$1.75)$ and $-0.0587(-17.06)$, respectively. Models 2 to 7 report results for each component of $U C_{-} P C A_{i t-1}\left(C C_{-} P C A_{i t-1}\right)$ after controlling for $C_{-} P C A_{i t-1}\left(U C_{-} P C A_{i t-1}\right)$. All the UC and CC component measures $\left(U C_{-} A C C_{i t-1}, U C_{-} B M_{i t-1}\right.$ and $U C_{-} R E S_{i t-1}, C C_{-} A C M_{i t-1}, C C_{-} A R A_{i t-1}$ and $\left.C C_{-} C R A_{i t-1}\right)$ are significantly negatively associated with subsequent $R l p m \_O C F_{i t}$ except for $U C_{-} B M_{i t-1}$, which is insignificantly negatively associated with subsequent $R l p m_{-} O C F_{i t}$. These results suggest that both $\mathrm{UC}$ and $\mathrm{CC}$ reduce future $\mathrm{OCF}$ downside risk as proxied by OCF RLPM, thus further corroborating hypothesis H1. Coefficients for control variables are qualitatively consistent with those reported in Table 3.

Table 5 reports results for the Fama-Macbeth regressions of subsequent OCF at risk $C F a R_{i t}$ on UC and CC measures and other controlling variables. In model $1, C F a R_{i t}$ is significantly negatively associated with both $U C_{-} P C A_{i t-1}$ and $C_{-} P C A_{i t-1}$, with coefficients ( $t$-statistics) of $0.1068(-10.69)$ and $-0.0448(-11.28)$, respectively. Models 2 to 7 indicate that all the other UC measures $U C_{-} A C C_{i t-1}, U C_{-} B M_{i t-1}$, and $U C_{-} R E S_{i t-1}$ are significantly negatively associated with subsequent $C F a R_{i t}$, and the other CC measures $C_{-} A C M_{i t-1}$ and $C C_{-} C R A_{i t-1}$ are significantly negatively associated with $C F a R_{i t}$, except that the coefficient on $C C_{-} A R A_{i t-1}$ is insignificant. Results for the controlling variables are generally consistent with those in Table $4 .{ }^{20}$ These findings suggest that both UC and CC reduce OCF downside risk proxied by OCF at risk CFaR, which reconfirms conclusions derived from Tables 3 and 4 strongly supporting hypothesis H1.

\subsection{Conservatism, Cash Holdings and OCF Downside Risk}

Table 6 presents 3SLS regression results for testing H2 that both UC and CC mitigate OCF downside risk via the cash holdings channel for both the full sample and a subsample without R\&D expenditures. The first-stage regressions of both 3SLS models orthogonalize conservatism

\footnotetext{
${ }^{20}$ We also use alternative measures for $C F a R$ calculated using confidence levels of $5 \%$ and $10 \%$ with results qualitatively unchanged.
} 
against cash holdings and demonstrate that previous cash holdings significantly decrease CC. ${ }^{21}$ $U C \_P C A$ and $C C_{-} P C A$ are significantly negatively associated with lagged Rlpm_OCF, suggesting that firms with higher OCF downside risk are likely to have less conservative and more aggressive accounting choices. The second-stage cash model for the full sample shows that both UC and CC significantly enhance subsequent cash holdings, with coefficients ( $t$-statistics) of 0.0165 (2.55) and $0.0120(4.52)$, respectively. In turn, cash holdings are significantly negatively associated with subsequent Rlpm_OCF in the third-stage regression, with a coefficient ( $t$-statistic) of $-0.0655(-8.24)$. These results suggest that cash holdings work as a mediating channel via which both $\mathrm{UC}$ and $\mathrm{CC}$ reduce OCF downside risk, with its meditating effect is equal to $-0.0011(=0.0165 *(-0.0655))$ for $\mathrm{UC}$ and $-0.0008(=0.0120 *(-0.0655))$ for $\mathrm{CC}$. These findings strongly support $\mathrm{H} 2$ regarding the cash holdings channel.

The 3SLS model analysis for the non-R\&D subsample addresses the concern that the observed evidence for the full sample is attributable to $R \& D$ expenditures that drive both the increase in cash holdings and the negative relation between cash holdings and OCF downside risk. It is evident that the 3SLS results for the non-R\&D subsample are qualitatively identical to those for the full sample analysis, thus dismissing $R \& D$ expenditures as an alternative explanation for our results. The third-stage Rlpm_OCF regressions in both 3SLS models further indicate that the interactions of UC and cash holdings are significantly negatively associated with Rlpm_OCF, suggesting that UC also indirectly affects OCF downside risk by enhancing the mitigating effects of cash holdings on OCF downside risk.

\subsection{Conservatism, Corporate Hedging and OCF Downside Risk}

Table 7 presents estimation results for the extended three-stage Heckman (1979) models examining $\mathrm{H} 3$ regarding the hedging channel. The $1^{\text {st }}$-stage UC_PCA and CC_PCA regressions

\footnotetext{
${ }^{21}$ This is explainable from three aspects. Firms holding more cash for risk management reasons reduces negative shocks to earnings, and these firms are also cautious in operations and investments, both of which naturally reduce the occurrence of bad earnings news; with sufficient cash in hand, firms have weak incentives to apply higher CC to obtain external financing at a lower cost of debt; firms with more free cash flows are subject to more serious agency problems and tend to withhold bad earnings news.
} 
in the first two columns address reverse causality between accounting conservatism and hedging and indicate that Hedger is significantly positively associated only with $U C_{-} P C A$, thus implying that hedging firms tend to choose higher UC as well. Lagged Rlpm_OCF is significantly negatively associated with both $U C_{-} P C A$ and $C_{-} C_{-} P C A$, suggesting that firms with higher OCF downside risk are likely to have less conservative reporting. The column " 2 nd - stage Probit Model for Hedger" shows that lagged $C C_{-} P C A_{i t-1}$ is significantly positively associated with the probability that a firm initiates a new hedging program, with a coefficient ( $t$-statistic) of 0.0705 (1.77). This evidence is consistent with the argument that timely warnings of rising risk exposures via $\mathrm{CC}$ promote corporate hedging activities. In contrast, $U C_{-} P C A_{i t-1}$ is significantly negatively associated with the probability that a firm initiates a new hedging program, with a coefficient ( $t$-statistic) of $-0.1587(-1.64)$. Combined with the $1^{\text {st }}$-stage results, these findings suggest that UC is a preferred choice for risk management possibly due to its low cost and consistent application, with UC substituting for hedging usage to some degree. ${ }^{22}$

The last column entitled " $3{ }^{\text {rd }}$-stage Model for Rlpm_OCF" report results for the third-stage difference-in-differences OLS regression after controlling for selection bias and other determinants. Initiating a hedging program significantly reduces subsequent OCF downside risk, as indicated by the significantly negative coefficient on interactions of Hedger and Post -0.1040 , a result consistent with Campello et al. (2010), Smith and Stulz (1985) and Stulz (1996). Combined with the second-stage results, this evidence implies that $\mathrm{CC}$ increases Hedger, which in turn reduces subsequent OCF downside risk, such that Hedger works as a mediating channel for $\mathrm{CC}$ to decrease OCF downside risk. A likely explanation is that by signaling bad news in a timely fashion, $\mathrm{CC}$ enhances monitoring and incentives to improve the effectiveness of ongoing hedging programs and to initiate productive new hedging programs that mitigate risk exposures

\footnotetext{
${ }^{22}$ Results for the controlling variables in the second-stage regression is generally consistent with the risk management literature; in particular, INT_BD, Leverage, Leverage*Invest_RD, ROA and SIZE are positively associated with all hedging types, whereas coefficients on $B \bar{A} S$ and $S I G M A$ are negative.
} 
and negative OCF shocks. This result is consistent with $\mathrm{H} 3$ in suggesting that $\mathrm{CC}$ complements hedging in reducing OCF downside risk. In addition, the 3rd-stage result that hedging usage mitigates OCF downside risk, combined with the findings from the 2nd-stage probit model that UC reduces hedging usage, confirm that UC substitutes for hedging in reducing OCF downside risk, consistent with $\mathrm{H} 3$. The 3rd-stage Rlpm_OCF model further demonstrates that the interaction of UC_PCA_R, Hedger, and Post is significantly positively associated with OCF downside risk, with a coefficient ( $t$-statistics) 0.0577 (2.34), implying that UC mitigates the effectiveness of Hedging for OCF downside risk. These findings provide further evidence that UC serves as a substitute for hedging.

\subsection{Exogenous Economic Shocks on Relations between Conservatism and OCF Downside Risk}

This section examines the effects of exogenous negative economic shocks proxied by downside cash flow covariance on relations between conservatism and OCF downside risk using the 3SLS model below. We use two downside cash flow covariance measures Dcfbetal and Dcfbeta2, which are defined as the ranking of industry adjusted downside cash flow beta, and industry and risk-free rate adjusted downside cash flow beta respectively, extending Ismail and Kim (1989) and Ang et al. (2006):

$$
\begin{aligned}
& \text { Shock }_{i t} \quad=\gamma_{0}+\gamma_{1} U C_{-} P C A_{i t-1}+\gamma_{2} C_{-} P C A_{i t-1}+\gamma_{2} \text { SIZE }_{i t-1}+\gamma_{3} \text { Leverage }_{i t-1} \\
& +\gamma_{4} R O A_{i t-1}+\gamma_{5} \text { Shock }_{i t-1}+\bar{\gamma}_{6} C E O \_ \text {Delta }_{i t-1}+\gamma_{7} \text { CEO_Vega } \text { it }-1_{1} \\
& +\Sigma b_{m} \text { Ind }_{m}+\Sigma b_{n} \text { Year }_{n}+\mu_{i t} \\
& \text { CON }_{i t}=\alpha_{0}+\alpha_{1} \text { SIZE }_{i t-1}+\alpha_{2} \text { Leverage }_{i t-1}+\alpha_{3} \text { ROA }_{i t-1}+\alpha_{4} \text { CON }_{i t-1}+\alpha_{5} \text { Shock_ }_{i t-1} \\
& +\alpha_{6} C E O \_D_{\text {Delta }}{ }_{i t-1}+\alpha_{7} C E O \_V e g a_{i t-1}+\Sigma b_{m} I_{n d}+\Sigma b_{n} \text { Year }_{n}+\mu_{i t} \\
& R l p m \_O C F_{i t}=\beta_{0}+\beta_{1} U C \_P C A_{-} R_{i t-1} * S h o c k \_R_{i t}+\beta_{2} C C_{-} P C A_{-} R_{i t-1} * \text { Shock } R_{i t} \\
& +\beta_{3} \text { Shock_R } R_{i t}+\text { Controls } 5_{i t-1}+\mu_{i t}
\end{aligned}
$$

where CON $=U C_{-} P C A$ and CC_PCA, Shock $=$ Dcfbeta1, Dcfbeta2, and Controls5 are the same as in model (7). The purpose of the first stage regression is to net out any potential effect of UC and $\mathrm{CC}$ on downside cash flow beta as firm-level accounting conservatism can impact the feedback of macro-economy by altering the measurement attributes of key macroeconomic indicators (Crawley 2012). The estimated residuals from equation (14), Shock_R, and from 
equation (15), $U C_{-} P C A_{-} R$ and $C C_{-} P C A_{-} R$, are used in the third-stage regressions. We expect that $\alpha_{5}>0$ and/or $\beta_{1}, \beta_{2}<0$, and Table 8 reports the results for the second and third-stage regressions.

Consistent with our conjecture, models 1 and 2 show that both measures of downside cash flow beta Dcfbetal and Dcfbeta2 are significantly positively associated with subsequent $U C_{-} P C A$ and $C C_{-} P C A$, which in turn are significantly negatively associated with future Rlpm_OCF. Moreover, the interactions of $U C_{-} P C A_{-} R_{i t-1}$ with downside OCF covariance measures Dcfbeta1_R, Dcfbeta2_R are significantly negatively associated with subsequent Rlpm_OCF. These findings support the notion that downside cash flow beta enhances the risk management role of $\mathrm{UC}$ and $\mathrm{CC}$ during economic downturns, thus reducing the adverse effects of shocks from the aggregate economy on firm-level OCF shortfalls.

\subsection{Sensitivity Tests}

\section{Alternative OCF Downside Risk Measurements}

To examine whether our results are robust to different OCF expectation models, we replace the OCF forecast model with the following OCF benchmarks: previous year industry mean of OCF, previous five-year mean of firm-specific OCF, and zero OCF. Then we recalculate the RRLPMs of OCF and denote them as DR_OCFind,DR_OCFpre and DR_OCFzero, respectively. To examine whether our results are robust to varied formulas for $R l p m \_O C F$, we alternatively define Rlpm_OCF2 as the natural logarithm of one plus the RLPM of OCF without deflating by the RUPM of OCF, and define Rlpm_OCF3 as the natural logarithm of one plus the RLPM of OCF deflated by the standard deviation of OCF. Panel A of Table 9 reports the estimation results for Fama and MacBeth (1973) regressions of these alternate OCF downside risk measures against lagged UC and CC measures, extending model (7). Models 1 to 5 reveal results qualitatively identical to those reported in Table 4.

To assess the effect of survival bias, we use a horizon of five rather three years to calculate 
Rlpm_OCF, with main results qualitatively unchanged. To address the concern that the estimation of the $C F a R$ may be unreliable because there are eight independent variables and the model is estimated using seventeen firm-quarter observations, we drop the quarter dummies and include only five variables in the quarterly OCF expectation model, with estimation results qualitatively unchanged.

\section{Alternative Accounting Conservatism Measurements}

Some prior studies use negative skewness $(S K E W)$ as a CC measure (e.g., Givoly and Hyan 2000). To test its effect, we estimate $C C_{-} S k e w$ as the predicted values of $S K E W_{i t}$ from the following OLS regression model to capture skewness caused by asymmetrical accrual timeliness:

$$
S K E W_{i t} \quad=\beta_{0}+\beta_{1} U C_{-} A C C_{i t}+\beta_{2} C C_{-} A C M_{i t}+\varepsilon_{i t} .
$$

We also calculate $C C_{-} P C A A$, the factor score generated from a PCA of $C C_{-} S k e w, C C \_A C M$ and $C C_{-} C R A$, and report the results for the logit model for $D O C F$ as well as Fama-Macbeth models for Rlpm_OCF and CFaR in Panel B of Table 10. Models 1 to 6 show that CC_Skew and CC_PCAA are significantly negatively associated with $R l p m \_O C F$ and $C F a R$, except for the insignificant result for $D O C F$, suggesting that our results are robust to alternative $\mathrm{CC}$ measures.

\section{Controls for Investors' Monitoring}

We use a 2SLS model to determine whether investor monitoring affects observed relations between conservatism and OCF downside risk. We add as further controls the negative of GScore, institutional ownership, board independence (ratio of the number of independent directors to board size) and debtholder monitoring (ratio of long-term debt to total debt) to the first-stage regression of $\mathrm{UC}$ or $\mathrm{CC}$, and to the second-stage regression of future Rlpm_OCF. ${ }^{23}$ We find that although these monitoring variables increase $\mathrm{UC}$ and $\mathrm{CC}$ and mitigate subsequent Rlpm_OCF, UC and CC continue to significantly reduce subsequent Rlpm_OCF.

\footnotetext{
${ }^{23}$ We obtain GScore and board structure data from RiskMetrics, institutional shareholdings data from Thomposon-Reuters Institutional Holdings database, board duality information from Execucomp as indicated by a current CEO also having the title of "chairman", "chmn", "Chairman", "CHAIRMAN", "Chmn" or "CHMN".
} 


\section{Controls for Earnings Smoothing}

Earnings smoothing has been characterized as a risk management tool that partially substitutes for hedging (Barton 2001). It is also associated with a phenomenon called "conservatism gaming", whereby higher conservatism during good economic times and lower conservatism during bad times generates a negative association between conservatism and bankruptcy risk (BMS 2012). Because conservatism is accrual-based and associated with earnings smoothing (BMS 2012), a potential concern arises as to whether the risk management role of accounting conservatism for OCF downside risk is robust to earnings smoothing. However, conservatism and earnings smoothing are not the same. For example, conservatism increases earnings volatility (Givoly and Hyan 2000; Ball and Shivakumar 2005, 2006) whereas earnings smoothing reduces earnings volatility (Barton 2001). Hence, we expect the risk management role of conservatism to be insensitive to earnings smoothing. To address the effects of earnings smoothing, we repeat all previous analyses by adding both innate and discretionary smoothing as additional controls. ${ }^{24}$ Untabulated results show that reported results are robust to their controls, with discretionary smoothing significantly positively associated with Rlpm_OCF and DOCF, consistent with the intuition of Graham, Harvey, and Rajgopal (2005) and Leuz, Nanda, and Wysocki (2003).

\section{Conclusion}

This study examines whether unconditional and conditional conservatism directly mitigate OCF downside risk, and whether they indirectly mitigate OCF downside risk via two established risk management instruments - cash holdings and corporate hedging. Our findings indicate that (1) both UC and CC directly mitigate subsequent OCF downside risk measured by the probability that a firm's future OCF deviates below its expected level, by OCF RRLPM, and by OCF at risk; (2) both UC and CC enhance cash holdings that reduce OCF downside risk; (3) UC

\footnotetext{
${ }^{24}$ Innate smoothing is measured as the product of negative one times the Spearman correlation between total accruals and OCF; discretionary smoothing is measured as the product of negative one times the ratio of the standard deviations of net income and OCF.
} 
(CC) serves as a substitute for (complement) new hedging programs that reduce OCF downside risk. Further tests for the effect of the exogenous economic condition of downside cash flow beta reveals it to enhance the mitigating effect of UC and CC on subsequent OCF downside risk. These findings are robust to alternate measures and specifications and lend support to accounting conservatism serving a risk mitigation role with respect to OCF downside risk.

This study contributes to the accounting conservatism literature by documenting relations between accounting conservatism and OCF downside risk, channels by which they operate, and conditioning by cash flow beta. They contribute to the risk management literature by establishing conservatism as an accounting-based instrument that firms can employ in concert with other risk management tools. They extend the downside risk literature by introducing three accounting-based OCF downside risk measures within the RRLPM and VaR frameworks that better control for growth effects and OFC asymmetry. They also contribute to a growing literature relating accounting information quality and economic recessions by providing evidence that the risk management effects of UC and CC strengthen during economic downturns. Our findings also have practical implications for economic policy-making and accounting standard-setting in suggesting conservatism as a relatively low-cost accounting-based risk management tool that is especially effective during economic downturns when exogenous economic shocks are severe. Finally, they help explain conservatism's longstanding use and standing as a central tenant of financial accounting and will help inform deliberations regarding its future.

This study's initial evidence regarding relations between accounting conservatism and OCF downside properties opens several avenues for future research. For instance, future studies can examine how conservatism affects other properties of cash holdings, other cash flows and additional firm attributes. Future studies can also consider relations between accounting conservatism on other risk dimensions and their implications for risk management tools for 
managers and policy makers. Importantly, these findings also lend support to further examinations of the costs and benefits of accounting conservatism as a longstanding feature and pervasive attribute of financial accounting. 


\section{References}

Acharya, V. V., H. Almeida, and M. Campello. 2007. Is Cash Negative Debt? A Hedging Perspective on Corporate Financial Policies. Journal of Financial Intermediation 16 (4): 515-554.

Ahmed, A. S., B. K. Billings, R. M. Morton, and M. Stanford-Harris. 2002. The Role of Accounting Conservatism in Mitigating Bondholder-Shareholder Conflicts over Dividend Policy and in Reducing Debt Costs. The Accounting Review 77 (4): 867-890.

Ahmed, A., and S. Duellman. 2007. Accounting Conservatism and Board of Director Characteristics: An Empirical Analysis. Journal of Accounting and Economics 43 (2-3): 411-437.

Altman, E. 1968. Financial Ratios, Discriminant Analysis and the Prediction of Corporate Bankruptcy. Journal of Finance 23 (4): 589-609.

Ang, A., J. Chen, and Y. Xing. 2006. Downside Risk. Review of Financial Studies 19 (4): 1191-1239.

Balakrishnan, K. 2009. Credit Market Conditions and Economy-wide Consequences of Financial Reporting Quality. Working paper, University of Pennsylvania.

Ball, R., R. Bushman, and F. Vasvari. 2008. The Debt-contracting Value of Accounting Information and Loan Syndicate Structure. Journal of Accounting Research 46 (2): 247-287.

Ball, R., and L. Shivakumar. 2005. Earnings Quality in UK Private Firms: Comparative Loss Recognition Timeliness. Journal of Accounting and Economics 39 (1): 83-125.

Ball, R., and L. Shivakumar. 2006. Role of Accruals in Asymmetrically Timely Gain and Loss Recognition. Journal of Accounting Research 44 (2): 207-242.

Baron, R. M., and D. A. Kenny. 1986. The Moderator-Mediator Variable Distinction in Social Psychological Research: Conceptual, Strategic, and Statistical Considerations. Journal of Personality and Social Psychology 51 (6): 1173-1182.

Barth, M. E., D. P. Cram, and K. K. Nelson. 2001. Accruals and the Prediction of Future Cash Flows. The Accounting Review 76 (1): 27-58.

Barth, M., W. Beaver, J. Hand, and W. Landsman. 2005. Accruals, Accounting-based Valuation Models, and the Prediction of Equity Values. Journal of Accounting, Auditing and Finance 20: 311345 .

Barton, J. 2001. Does the Use of Financial Derivatives Affect Earnings Management Decisions. The Accounting Review 76 (1): 1-26.

Basu, S. 1997. The Conservatism Principle and the Asymmetric Timeliness of Earnings. Journal of Accounting and Economics 24 (1): 3-37.

Bates, T. W., M. K. Kathleen, and R. Stulz. 2009. Why Do U.S. Firms Hold So Much More Cash than They Used To? Journal of Finance 64 (5): 1985-2021.

Beatty, A., and S. Liao. 2011. Regulatory Capital Ratios, Loan Loss Provisioning and Procyclicality. Journal of Accounting and Economics 52 (1): 1-20.

Bergemann, D., U. Hege, and L. Peng. 2011. Venture Capital and Sequential Investments. Working paper, Yale University.

Biddle, G. C. 1980. Accounting Methods and Management Decisions: The Case of Inventory Costing and Inventory Policy. Journal of Accounting Research 18 (Supplement): 235-280.

Biddle, G. C., M. L. Ma, and F. Song. 2012. Accounting Conservatism and Bankruptcy Risk. Working paper, University of Hong Kong.

Bodnar, G., G. Hayt, and R. Marston. 1998. Wharton Survey of Financial Risk Management by US 
Non-financial Firms, Financial Management 27, 70-91.

Brown, L. D., and M. S. Rozeff. 1979. Univariate Time-series Models of Quarterly Accounting Earnings Per Share: A Proposed Model. Journal of Accounting Research 17 (1): 179-189.

Callen, J., J. Livnat, and D. Segal. 2006. The Information Content of SEC Filings and Investor Sophistication: A Variance Decomposition Analysis. The Accounting Review 81 (5): 1017-1043.

Campello, M., C. Lin, Y. Ma, and H. Zou. 2011. The Real and Financial Implications of Corporate Hedging. Journal of Finance 66 (5): 1615-1647.

Crawley, M. 2012. Macroeconomic Consequences of Accounting: The Effect of Accounting Conservatism on Macroeconomic Indicators and the Money Supply. Working paper, Indiana University.

Dechow, P. 1994. Accounting Earnings and Cash Flows as Measures of Firm Performance: The Role of Accounting Accruals. Journal of Accounting and Economics 18 (1): 3-42.

Dechow, P., S. P. Kothari, and R. Watts. 1998. The Relation between Earnings and Cash Flows. Journal of Accounting and Economics 25 (2): 133-168.

Disatnik, D., R. Duchin, and B. Schmidt. 2012. Cash Flow Hedging and Liquidity Choices. Working paper, University of Michigan.

Driouchi, T., and D. Bennett. 2010. Real Options in Multinational Decision-making: Managerial Awareness and Risk Implications. Journal of World Business 46 (2): 205-219.

Dutta, P. K., and R. Radner. 1999. Profit Maximization and the Market Selection Hypothesis. The Review of Economic Studies 66 (4): 769-798.

Fama, E. F., and K. R. French. 1997. Industry Costs of Equity. Journal of Financial Economics 43 (2): 153-192.

Fama, E. F., and J. MacBeth. 1973. Risk, Return, and Equilibrium: Empirical Tests. Journal of Political Economy 81 (3): 607-636.

Financial Accounting Standards Board. 1980. Statement of Financial Accounting Concepts No. 2. Qualitative Characteristics of Accounting Information.

Financial Accounting Standards Board. 1987. Statement of Financial Accounting Standards (SFAS) No. 95: Statement of Cash Flows.

Financial Accounting Standards Board. 2008. Conceptual Framework for Financial Reporting: The Objective of Financial Reporting and Qualitative Characteristics and Constraints of Decision-useful Financial Reporting Information. Exposure Draft, Financial Accounting Series No. 1570-100.

Financial Accounting Standards Board. 2010. Statement of Financial Accounting Concepts No. 8. Conceptual Framework for Financial Reporting.

Fishburn, P. C. 1977. Mean-risk Analysis with Risk Associated with Below Target Return. American Economic Review 67 (2): 116-126.

Francis, J., and X. Martin. 2010. Acquisition Profitability and Timely Loss Recognition. Journal of Accounting and Economics 49 (1-2): 161-178.

Froot, K. A., D. S. Scharfstein, and J. C. Stein. 1993. Risk Management: Coordinating Corporate Investments and Financing Policies. Journal of Finance 48 (5): 1629-1658.

Gamba, A. and A. Triantis. 2011. Corporate Risk Management: Integrating liquidity, hedging, and operating policies. Working paper, Robert H. Smith School Research Paper No. RHS 06-106.

Gao, P., and P. J. Liang. 2011. Informational Feedback Effect, Adverse Selection, and the Optimal 
Disclosure Policy. Working paper, University of Chicago.

Gigler, F., C. Kanodia, H. Sapra, and R. Venugopalan. 2009. Accounting Conservatism and the Efficiency of Debt Contracts. Journal of Accounting Research 47 (3): 767-97.

Givoly, D., and C. Hayn. 2000. The Changing Time-series Properties of Earnings, Cash Flows and Accruals: Has Financial Reporting Become More Conservative? Journal of Accounting and Economics 29 (3): 287-320.

Graham, J. R., C. R. Harvey, and S. Rajgopal. 2005. The Economic Implications of Corporate Financial Reporting. Journal of Accounting and Economics 40 (1-3): 3-73.

Guay, W. R. 1999. The Impact of Derivatives on Firm Risk: An Empirical Examination of New Derivative Users. Journal of Accounting and Economics 26 (1-3): 319-351.

Heckman, J. 1979. Sample Selection Bias as a Specification Error. Econometrica 47 (1): 153-161.

Hribar, P., and D. W. Collins. 2002. Errors in Estimating Accruals: Implications for Empirical Research. Journal of Accounting Research 40 (1): 105-134.

Hui, K. W., S. Klasa, and E. Yeung. 2012. Corporate Suppliers and Customers and Accounting Conservatism. Journal of Accounting and Economics 53 (1-2): 115-135.

Ismail, B. E., and M. K. Kim. 1989. On the Association of Cash Flow Variables with Market Risk: Further Evidence. The Accounting Review 64 (1): 125-136.

Jensen, M. C. 1986. Agency Cost of Free Cash Flow, Corporate Finance and Takeovers. The American Economic Review 76 (2): 323-329.

Khan, M., and R. Watts. 2009. Estimation and Empirical Properties of a Firm-year Measure of Conservatism. Journal of Accounting and Economics 48 (2-3): 132-150.

Kim, M., and W. Kross. 2005. The Ability of Earnings to Predict Future Operating Cash Flows Has Been Increasing - Not Decreasing. Journal of Accounting Research 43 (5): 753-780.

Kirschenheiter, M., and R. Ramakrishnan. 2010. Prudence Demands Conservatism. Working paper, University of Illinois at Chicago.

Koonce, L., M. L. McAnally, and M. Mercer. 2005a. How Do Investors Judge the Risk of Derivative and Non-Derivative Financial Items? The Accounting Review 80 (1): 221-241.

Koonce, L., M. Lipe, and M. McAnally. 2005b. Judging the Risk of Financial Instruments: Problems and Potential Remedies. The Accounting Review 80 (3): 871-895.

LaFond, R., and R. Watts. 2008. The Information Role of Conservatism. The Accounting Review 83 (2): 447-478.

Leuz, C., D. Nanda, and P. Wysocki. 2003. Earnings Management and Investor Protection: An International Comparison. Journal of Financial Economics 69 (3): 505-527.

Li, Y., 2010. Accounting Conservatism and the Consequences of Covenant Violations. Working paper, University of Lethbridge.

Lins, K., H. Servaes, and P. Tufano. 2010. What Drives Corporate Liquidity? An International Survey of Cash Holdings and Lines of Credit. Journal of Financial Economics 98 (1): 160-176.

Lorek, K. S., T. F. Schaefer, and G. L. Willinger. 1993. Time-series Properties and Predictive Ability of Funds Flow Variables. The Accounting Review 68 (1): 151-163.

Lorek, K. S., and G. L. Willinger. 1996. A Multivariate Time-series Prediction Model for Cash-flow Data. The Accounting Review 71 (1): 81-101.

Lorek, K. S., and G. L. Willinger. 2008. Time-series Properties and Predictive Ability of Quarterly 
Cash Flows. Advances in Accounting 24 (1): 65-71.

Louis, H., A. Sun, and O. Urcan. 2012. Value of Cash Holdings and Accounting Conservatism. Contemporaneous Accounting Research, forthcoming.

Luo, L., and R. Watts. 2011. Accounting Conservatism and Firm Value: Evidence from the Global Financial Crisis. Working paper, MIT.

Menezes, C., C. Geiss, and J. Tressler. 1980. Increasing Downside Risk. American Economic Review 70 (5): 921-932.

Miller, K. D., and K. K. Reuler. 1996. Measuring Organizational Downside Risk. Strategic Management Journal 17 (9): 671-691.

Minton, B., and C. Schrand. 1999. The Impact of Cash Flow Volatility on Discretionary Investment and the Costs of Debt and Equity Financing. Journal of Financial Economics 54 (3): 423-60.

Minton, B., C. Schrand, and B. Walther. 2002. The Role of Volatility in Forecasting. Review of Accounting Studies 7 (2-3): 195-215.

Modigliani, F., and M. H. Miller. 1958. The Cost of Capital, Corporation Finance and the Theory of Investment. American Economic Review 48 (5): 261-297.

Opler, T., L. Pinkowitz, R. Stulz, and R. Williamson. 1999. The Determinants and Implications of Corporate Cash Holdings. Journal of Financial Economics 52 (1): 3-46.

Opler, T. C., and S. Titman. 1994. Financial Distress and Corporate Performance. Journal of Finance 49 (3): 1015-1040.

Penman, S. H., and X. Zhang. 2002. Accounting Conservatism, the Quality of Earnings, and Stock Returns. The Accounting Review 77 (2): 237-264.

Rawls, S. W., and C. W. Smithson. 1993. Strategic Risk Management. In Donald H. Chew Jr. (Ed.), The New Corporate Finance, Where Theory Meets Practice. McGraw-Hill.

RiskMetrics. 1999. CorporateMetrics ${ }^{T M}$ Technical Document.

Roy, A. D. 1952. Safety First and the Holding of Assets. Econometrica 20 (3): 431-449.

Ryan, S. G. 2006. Identifying Conditional Conservatism. European Accounting Review 15 (4): 511 525 .

Smith, C. W., and R. M. Stulz. 1985. The Determinants of Firms' Hedging Policies. Journal of Financial and Quantitative Analysis 20 (4): 391-405.

Stein J. C., S. E. Usher, D. LaGattuta, and J. Youngen. 2001. A Comparables Approach to Measuring Cash-flow-at-risk for Non-financial Firms. Journal of Applied Corporate Finance 13 (4): 8-18.

Stulz, R. M. 1996. Rethinking Risk Management. Journal of Applied Corporate Finance 9 (3): 8-24.

Stone, B. K. 1973. A General Class of Three-parameter Risk Measures. Journal of Finance 28 (3): 675-685.

Tian, X., D. Collins, and P. Hribar. 2009. The Confounding Effects of Operating Cash Flow Asymmetric Timeliness on the Basu Measure of Conditional Conservatism. Working Paper, University of Iowa.

Tversky, A., and D. Kahneman. 1991. Loss Aversion in Riskless Choice: A Reference-Dependent Model. Quarterly Journal of Economics 106 (4): 1039-1061.

Watts, R., and J. Zimmerman. 1986. Positive Accounting Theory. Prentice-Hall, Inc.

Watts, R. 2003. Conservatism in Accounting Part I: Explanations and Implications. Accounting 
Horizons 17 (3): 207-221.

Wittenberg-Moerman, R. 2008. The Role of Information Asymmetry and Financial Reporting Quality in Debt Contracting: Evidence from the Secondary Loan Market. Journal of Accounting and Economics 46 (2-3): 240-260.

Zhang, J. 2008. The Contracting Benefits of Accounting Conservatism to Lenders and Borrowers. Journal of Accounting and Economics 45 (1): 27-54.

Zhang, H. 2009. Effect of Derivative Accounting Rules on Corporate Risk-management Behavior. Journal of Accounting and Economics 47 (3): 244-264. 


\section{Appendix A Benchmark Models for Operating Cash Flows}

This study utilizes the following prediction model for expected OCF:

$$
\begin{aligned}
O^{O C F_{t+1}} & =\beta_{0}+\beta_{1} O C F_{t}+\beta_{2} O C F_{t-1}+\beta_{3} O C F_{t-2}+\beta_{4} S A L E_{t}+\beta_{5} S I Z E_{t}+\beta_{8} L E V E R A G E_{t} \\
& +\beta_{6} S T D \_O C F_{t}+\text { Year_Dummies }+\varepsilon_{t+l} .
\end{aligned}
$$

Model (a1) combines an autoregressive AR (3) structure for the time series of OCF and the economic determinants of OCF. Dechow et al. (1998) report that an AR (3) model for OCF improves predictability. In Model (a1), the ratio of total sales to total assets $S A L E$ is a major determinant of both OCF and earnings as suggested by Barth Cram, and Nelson (2001) and Dechow et al. (1998). Further, SALE is a substitute for earnings, another determinant of the predictability of future OCF (e.g., Barth, Beaver, Hand, and Landsman 2005; Kim and Kross 2005), but without introducing endogeniety between conservatism and OCF downside risk unlike accrual-based earnings. Both SIZE and operating cycle $(O C)$ have been employed as determinants for OCF expectation models in prior research (Dechow et al. 1998). However, Hui et al. (2012) suggest that conservatism may shorten operating cycles by increasing trading contract efficiencies. Therefore, we omit $O C$ from Model (a1). Model (a1) also includes Leverage whose impact on OCF is difficult to predict. Opler and Titman (1994) document that financially distressed firms lose significant market share to healthier counterparts during industry downturns, and Froot et al. (1993) suggest that higher leverage causes firms to forgo positive $N P V$ projects due to costly external financing. Leverage $_{t}$ could also proxy for interest expenses since firm size is controlled. SFAS No. 95 requires interest expenses to be reported as an OCF rather than as a financing flow, which would create a negative mechanical relation between Leverage and the subsequent OCF. However, high Leverage also implies that firms already use sufficient external financing to support operations and investment activities, which tends to increase subsequent OCF. Therefore, the relation between Leverage and OCF is an open empirical question. Industry cash flow risk is a determinant of the predictability of OCF, yet estimation by industry already serves to control for its effects. In addition, firm-specific cash flow risk tends to increase cash flow uncertainty and difficulties in predicting OCF (Minton et al. 2002). Thus, STD_OCF is included in Model (a1) and is calculated as the volatility of quarterly OCF over the current and previous eleven fiscal quarters, with a minimum of four quarters of OCF data. ${ }^{25}$ Lastly, year $^{-}$ dummies are included to capture temporal factors that impact OCF predictability.

Following the intuition of Stein et al. (2001), we delete firm-years below the lower-end 5\% of total assets for a given fiscal year to alleviate concerns that small firm size could disproportionately inflate the OCF ratio and bias OCF predictions, which results in 73,598 firm-year observations. We fit Model (a1) by Fama-French (1997) industry classifications, and the average R-square is $0.2390 .^{26}$ The coefficients on $O C F_{t}, O C F_{t-2}, S A L E_{t}$ and $S I Z E_{t}$ are significantly positive in most industries, and the coefficients on Leverage are mixed (significantly positive in eight industries and significantly negative in seven industries), consistent with prior evidence. The means and $t$ statistics of the estimated coefficients for Model (a1) are as follows:

$$
\begin{aligned}
O C F_{t+1}= & -0.0016+0.2407 * O C F_{t}+0.0158 * O C F_{t-1}+0.0157 * O C F_{t-2}+0.0339 * S A L E_{t} \\
& (-0.08)(4.73) * * * \quad(0.85) \\
+ & 0.0092 * S I Z E_{t}-0.01 * L E V E R A G E_{t}-0.0048 S T S_{-} O C F_{t}+\text { Year_Dummies } \\
& (6.26) * * *(-0.00)
\end{aligned}
$$

When the market value of equity is used to deflate OCF, results are qualitatively unchanged. Estimated residuals and fitted values from Model (a1) are used to calculate DOCF and Rlpm_OCF for our main tests. In robustness tests, we also use ROA instead of $S A L E$ in Model (a1) and results are qualitatively unchanged, indicating that endogeneity is not a serious concern. We also include operating cycle $O C$ in Model (a1). We define $O C$ as the average time between purchasing or acquiring inventory and receiving cash from their sales, and gauge it as the natural logarithm of 360 days times the ratios of average accounts receivable (Compustat RECT) to total revenue (Compustat SALE), and of average inventory (Compustat INVT) to cost of goods sold (Compustat COGS). The coefficients on $O C$ is insignificant for most industries, the addition of $O C$ does not greatly improve the $R$-square, and the empirical results are qualitatively unchanged, suggesting that any conservatism bias caused by $O C$ is not a serious concern.

\footnotetext{
${ }^{25}$ We use quarterly data to estimate cash flow risk $S T D \_O C F . S T D \_O C F$ thus calculated is positively correlated with $S T D \_O C F$

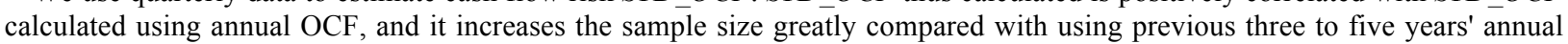
OCF data.

${ }^{26}$ This model is fitted by industry rather than by year because OCF properties are shaped more by industry features. The average $R$-square drops from about $24 \%$ to $18 \%$ when the model is fitted by fiscal year with industry dummies.
} 


\section{Appendix B Comparables Approach for Cash Flow at Risk (CFaR)}

Extending Stein et al. (2001), this study uses a comparables approach to calculate OCF at risk, $C F a R$, using quarterly data from 1993 to 2007. The estimation procedures are as follows:

1. Delete firm-quarters with total assets in the lowest $5 \%$ tails for each quarter so that the ratio of quarterly OCF to total assets $O C F Q$ will not be biased upwards due to small firm size problem (Stein et al. 2001). Also remove firm-quarters that experience changes in total assets of more than $50 \%$ in a quarter due to M\&A activities, capital expenditures, or other dramatic changes.

2. Starting from the first fiscal quarter of 1993 , fit the following $O C F Q$ benchmark model using cross-sectional data over a rolling window of seventeen fiscal quarters, including the current quarter $t$, and sixteen previous fiscal quarters:

$$
O C F Q_{t}=\beta_{0}+\beta_{1} O C F Q_{t-1}+\beta_{2} O C F Q_{t-2}+\beta_{3} O C F Q_{t-3}+\beta_{4} O C F Q_{t-4}+\gamma_{1} Q_{1}+\gamma_{2} Q_{2}+\gamma_{3} Q_{3}+\varepsilon_{t},
$$

where $Q_{1}$ to $Q_{3}$ are dummies for the first to third fiscal quarters, respectively. ${ }^{27}$ The rolling window allows the target quarter $t$ to have at most seventeen observations to fit the model for each industry. The rationale for this model is as follows. Lorek and Willinger (2008) report that the parsimonious (100)*(011) ARIMA model of quarterly OCF in Brown and Rozeff (1979) performs the best among all documented quarterly OCF estimation models (Lorek, Schaefer, and Willinger 1993; Lorek and Willinger 1996). ${ }^{28}$ However, the Brown-Rozeff model is a univariate parsimonious model that ignores economic determinants of quarterly OCF and information in lag two and three of $O C F Q$ because it assumes that the fourth differences in quarterly OCF follow an AR (1) process. Stein et al. (2001) alternatively recommend an AR (4) model with dummies for each quarter capturing earnings seasonality. Combining the merits of both types of models arrives at Model (b2) below with quarter dummies capturing seasonality and unobserved firm-specific determinants:

$O C F Q_{t} \quad=\beta_{0}+\beta_{1} O C F Q_{t-1}+\beta_{2} O C F Q_{t-2}+\beta_{3} O C F Q_{t-3}+\beta_{4} O C F Q_{t-4}+\beta_{5} O C F Q_{t-5}+\gamma_{1} Q_{1}+\gamma_{2} Q_{2}+\gamma_{3} Q_{3}+\varepsilon_{t}(\mathrm{~b} 2)$

Model (b2) includes the fifth lag of $O C F Q$ but relaxes the restrictive assumption regarding the fourth difference that underlies the Brown-Rozeff (1979) model. However empirical results show that the coefficient on $O C F_{t-5}$ is insignificant, so we omit the fifth lag, and Model (b2) collapse into Model (b1), the model we use to calculate $C F a R$.

3. For each firm-quarter observation, calculate $O C F Q$ forecast errors, the deviations of actual $O C F Q$ to its predicted value, as the estimated residual $\dot{\varepsilon}_{t}$ from the benchmark model (b1).

4. Take the natural logarithm of the squared $O C F Q$ forecast error $\left(\dot{\varepsilon}_{t}^{*} \dot{\varepsilon}_{t}\right)$ and regress it on market capitalization $(M V)$, annual asset turnover (SALE), stock volatility (Sigma), and Fama-French (1997) industry dummies. Use coefficients on industry dummies to represent the industry cash flow risk for estimating $O C F Q$ forecast errors.

5. Sort the $O C F Q$ forecast errors $\left(\dot{\varepsilon}_{t}\right)$ for the seventeen quarters along the following four dimensions for each quarter $t:$ (1) $M V$; (2) $S A L E ; ;^{29}$ (3) industry cash flow risk estimated from Step 4; and (4) Sigma calculated using daily price over the prior quarter. Put another way, $\dot{\varepsilon}_{t} \mathrm{~s}$ are first sorted into four buckets by market capitalization, and then each bucket is subdivided into four buckets by asset turnover. Each sub-bucket is further divided into four buckets based on industry risk, and each of the resulting sixty-four buckets is further subdivided into four sub-buckets in terms of Sigma. Ultimately, we get $4 * 4 * 4 * 4=256$ sub-buckets for each quarter, each possessing approximately 160-200 forecast errors with relatively homogenous characteristics along these four dimensions. The roughly 160-200 forecast errors in each bin can reasonably describe a target firm-quarter's distribution of forecast errors, and the lowest forecast errors at the $1 \%, 5 \%$, and $10 \%$ confidence levels are assigned to each target firm-quarter in each bin. Then $C F a R$ for that quarter is calculated as negative one times that assigned forecast error divided by the fitted expected $O C F Q$ from Model (b1), and only the CFaR for the last quarter is kept. The above procedures are repeated for each successive quarter through the fourth quarter of 2007, and we only use only the 4th quarter $C F a R$ data to merge with our main sample.

This comparables approach for estimating $C F a R$ offers several advantages: First, within any given peer group, the model produces relatively reasonable estimates on average. Second, the model is non-parametric in that it obtains each forecast error from an expectation model that is peer-benchmarked by risk, thereby avoiding imposing the unrealistic assumption that shocks to $O C F Q$ are parametrically distributed. However, this method is sensitive to the expectation model employed because it attributes all the forecast errors to the estimated $C F a R$, assuming away any estimation error.

\footnotetext{
${ }^{27}$ Similar to the adjustment to $O C F$ in Model (a1), this study also adjusts quarterly OCF by adding back concurrent R\&D and marketing expenditures. This treatment mitigates the concern that the immediate expensing of R\&D and marketing costs causes a mechanical negative relationship between $O C F$ and hidden reserve $U C \_R E S$.

${ }^{28}$ The Brown and Rozeff (1979) model is expressed as $O C F_{t}=O C F_{t-4}+\varphi_{2}\left(O C F_{t-1}-O C F_{t-5}\right)+\varepsilon_{t}-\theta_{l} \varepsilon_{t-4}$.

${ }^{29}$ Stein et al. (2001) use earnings as a partitioning variable. Instead, this study uses the ratio of sales to assets because it is less subject to conservatism bias and is the most important variable that affects bankruptcy risk (Altman 1968). The ratio of sales to assets is calculated as the sum of the previous four periods' sales to the previous four periods' total assets.
} 
Table 1 Descriptive Statistics for Main Variables

This table reports summary statistics for the full sample of firm-year observations from 1992 through 2007. Variable definitions are presented at the bottom of the table.

\begin{tabular}{|c|c|c|c|c|c|}
\hline Variables & Mean & STD & Q1 & Median & Q3 \\
\hline DOCF & 0.5798 & 0.4936 & 0 & 1 & 1 \\
\hline$R l p m \_O C F(R a w)$ & 0.0936 & 0.2970 & -0.0715 & 0.0360 & 0.1321 \\
\hline $\operatorname{CFaR}(\operatorname{Raw})$ & 0.5329 & 9.5376 & 0.1133 & 0.2018 & 0.3410 \\
\hline$U C_{-} P C A$ & 0.3778 & 0.2170 & 0.1953 & 0.3809 & 0.5613 \\
\hline$U C_{-} A C C$ & 0.0027 & 0.0461 & -0.0197 & 0.0027 & 0.0241 \\
\hline$U \bar{C} B M(R a w)$ & 0.3051 & 3.8507 & -0.1301 & 0.1500 & 0.4684 \\
\hline$U C_{-} R E S$ & 0.0897 & 0.2732 & 0 & 0.0242 & 0.1049 \\
\hline$C_{-}^{-} P C A$ & 0.6162 & 0.3283 & 0.3731 & 0.6144 & 0.8594 \\
\hline$C C_{-}^{-} A C M$ & -0.0002 & 0.0822 & -0.0305 & 0.0072 & 0.0362 \\
\hline$C C_{-} A R A(R a w)$ & -0.5937 & 23.0188 & -0.7546 & -0.7133 & -0.6550 \\
\hline$C C_{-} C R A(R a w)$ & -0.0633 & 8.0455 & -0.7135 & -0.3564 & 0.6566 \\
\hline Cash & 0.1209 & 0.1477 & 0.0195 & 0.0636 & 0.1674 \\
\hline Dcfbeta1(Raw) & 0.0742 & 33.8940 & -0.0194 & 0.0716 & 0.6005 \\
\hline Dcfbeta2(Raw) & 0.0774 & 35.1553 & 0.0031 & 0.1045 & 0.6608 \\
\hline Invest_CAPX & 0.0627 & 0.4102 & 0.0223 & 0.0429 & 0.4102 \\
\hline Invest_RD & 0.0291 & 0.0612 & 0 & 0 & 0.0325 \\
\hline$\triangle$ Cash & -0.0068 & 0.9585 & -0.0133 & 0.0028 & 0.0307 \\
\hline DISSUE & 0.0040 & 0.0528 & 0 & 0 & 0 \\
\hline DIV & 0.0072 & 0.0216 & 0 & 0 & 0.0064 \\
\hline Leverage & 0.1925 & 0.1621 & 0.0357 & 0.1775 & 0.3061 \\
\hline LOSS & 0.1774 & 0.3820 & 0 & 0 & 0 \\
\hline$N W C$ & 0.1062 & 0.1963 & -0.0207 & 0.0831 & 0.2295 \\
\hline$O O$ & 0.5835 & 0.3978 & 0.2806 & 0.5012 & 0.8114 \\
\hline $\boldsymbol{R O A}$ & 0.0371 & 0.1011 & 0.0149 & 0.0484 & 0.0840 \\
\hline Growth & 0.0084 & 4.6875 & 0.0030 & 0.0803 & 0.1623 \\
\hline$I N T$ & 0.0032 & 0.0097 & 0 & 0 & 0.0020 \\
\hline NOL & 0.0777 & 0.2677 & 0 & 0 & 0 \\
\hline Sigma & 0.4576 & 0.2476 & 0.2877 & 0.3993 & 0.5579 \\
\hline$S I Z E$ & 1.8449 & 0.3250 & 1.6326 & 1.8813 & 2.0804 \\
\hline$S L A C K$ & -0.3435 & 2.2937 & -0.3728 & -0.1488 & 0.0256 \\
\hline SLACK_EMP & -0.0051 & 0.1727 & -0.0049 & -0.0019 & 0.0005 \\
\hline CEO_Delta & 0.0076 & 0.0381 & 0 & 0 & 0.0004 \\
\hline $\mathrm{CEO}_{-} \mathrm{Vega}$ & 0.0970 & 0 & 0 & 0.0056 & 1.1365 \\
\hline$I N T \_B D$ & 0.1451 & 5.1587 & 0 & 0.0834 & 0.2452 \\
\hline$B A \bar{S}$ & 0.0219 & 0.0274 & 0.0044 & 0.0136 & 0.0274 \\
\hline
\end{tabular}

$D O C F$ is a dummy variable indicating that actual OCF is belower OCF expection estimated from a benchmark OCF model for a given firm-year. It is equal to 1 if the residual from the OCF benchmark model is negative, and 0 otherwise. Rlpm_OCF is the ranked natural logarithm of the ratio of one plus OCF root lower partial moment, over one plus OCF root upper partial moment calculated in the current and previous two years. Refer to the text and Appewndix A for expectation models for both $D O C F$ and Rlpm_OCF.CFaR is the ranked percentage shortfall below expected quarterly OCF at a $1 \%$ confidence level estimated from a probability distribution of firm-quarter OCF of the firm and its comparable peers using a non-parametric approach. The expectation model for quarterly OCF is detailed in Appendix B. $U C_{-} P C A$ is the factor score from a PCA of three UC measures: $U C \_A C C, U C_{-} B M$ and $U C_{-} R E S$. UC_ACC is equal to minus one times total accruals to average total assets, calculated over a rolling window of current year and prior two years, where total accruals are calculated as: Total accruals ${ }_{i t}=$ net income before extraordinary items it $_{\text {(Compustat IB) - operating cash flow }}$ (Compustat OANCF) + depreciation expense $\mathrm{i}_{\mathrm{it}}(\mathrm{Compustat} \mathrm{DP})$. $U C_{-} B M$ is the industry-adjusted ranking of minus one times book to market value of common equity at the fiscal year-end. $U C_{-} R E S$ is hidden reserve resulting from LIFO, $\mathrm{R} \& \mathrm{D}$ and marketing expenses to total assets. $C C_{-} P C A$ is the factor score from a PCA of three CC measures: $C C_{-} A C M, C C_{-} A R A$ and $C C_{-} C R A$. $C C_{-} A C M$ is equal to minus one times accumulated nonoperating accruals to accumulated total assets, calculated over a rolling window of the current year and prior two years, with non-operating accruals calculated as Total accruals - $\triangle$ accounts receivable (Compustat RECT) - $\triangle$ inventories (Compustat INVT) - Aprepaid expenses (Compustat XPP) + $\Delta$ accounts payable (Compustat AP) + $\Delta$ taxes payable (Compustat TXP). CC_ARA is equal to the ranked ratio of the sum of $C$ score and $G$ score over $G$ score, with $C$ score and $G$ score estimated from an extended model from Khan and Watts (2009) detailed in the text. $C C_{-} \bar{C} R A$ is equal to current accrual shocks to total accrual news for bad accrual news, with the ratio multiplied by -1 for good accrual news cases, adapting Callen et al. (2006). Cash is cash holdings (Compustat CHE) to total assets (Compustat AT). Defbetalis an accounting-based measure for downside OCF covariance during economic downturns relative to upturns and is calculated as the ranking of industry adjusted downside OCF covariance. Dcfbeta2 is an accounting-based measure for downside $O C F$ covariance during economic downturns relative to 
upturns and is calculated as the ranking of industry and risk-free rate adjusted downside $O C F$ covariance. $\triangle$ Cash is cash flow (Compustat $\mathrm{CHECH}$ ) to total assets (Compustat AT). Dissue is net long-term debt issuance (Compustat DLTIS) over long-term debt reduction (Compustat DLTR) to total assets (Compustat AT). DIV is cash dividend (Compustat DV) to total assets (Compustat AT). Growth is sales changes to sales (Compustat SALE) for the previous year. Invest_CAPX is capital expenditures (Compustat CAPX) to total assets (Compustat AT). Invest_RD is R\&D expenditures (Compustat XRD) to total assets (Compustat AT). Leverage is book value of long-term debt (Compustat DLTT) and short-term debt (Compustat DLC) to total assets (Compustat AT). LOSS is a dummy variable equal to one if a firm has negative income for the current fiscal year, and zero otherwise. $N W C$ is working capital (Compustat WCAP) net of cash holdings (Compustat CHE) to total assets (Compustat AT). $O O$ is total property, plant and equipment (Compustat PPEGT) to total assets (Compustat AT). ROA is net income to assets (Compustat AT). Sigma is the annualized standard deviation of monthly stock return over the prior twelve months. SIZE is the natural logarithm of the sum of the market value of equity (Compustat PRCC_F, Compustat CSHO), total liabilities (Compustat LT), and the carrying value of preferred stock (Compustat PSTK). SLACK is the average of the industryadjusted ratio of inventory (Compustat INVT) to total revenue (Compustat SALE), of accounts receivable (Compustat RECT) to total revenue (Compustat SALE), and of selling, general and administrative expense (Compustat XSGA) to total revenue (Compustat SALE). SLACK_EMP is the industry-adjusted ratio of total number of employees at fiscal year-end (Compustat EMP) to total revenue (Compustat SALE). INT BD is interest expense (Compustat XINT) to operating income before depreciation and interest (Compustat OPINCAR). INT is the interaction of R\&D investment (Invest RD) and leverage ratio (Leverage). NOL is an indicator variable equal to one for positive net income and positive net operating loss carry forwards, and zero otherwise. CEO Vega is the natural logarithm of the sensitivity of CEO's firm-specific equity-based wealth to a $1 \%$ change in the firm's stock return volatility. CEO_Delta is the natural logarithm of the sensitivity of CEO's firm-specific equity-based wealth to a $1 \%$ change in stock price. BAS is the average daily percentage bid ask spread in the fiscal year. 
Table 2 Correlation Matrix for Main Testing Variables for the Full Sample

This table reports pairwise correlations among downside risks metrics and accrual-based conservatism measures, cash holdings, hedging dummy, and downside cash flow betas. The upper triangle displays Pearson correlations and the lower triangle displays Spearman correlations. Highlighted figures indicate statistical significance beyond the $90 \%$ confidence level. All variable definitions except for Hedger are presented at the bottom of Table 1

\begin{tabular}{|c|c|c|c|c|c|c|c|c|c|c|c|c|c|c|c|}
\hline Variables & 1 & 2 & 3 & 4 & 5 & 6 & 7 & 8 & 9 & 10 & 11 & 12 & 13 & 14 & 15 \\
\hline 1. DOCF & 1 & 0.6451 & 0.0115 & -0.0508 & -0.0078 & -0.0407 & -0.0581 & -0.0165 & -0.0256 & -0.0599 & -0.0188 & -0.0497 & -0.0262 & -0.0191 & -0.0183 \\
\hline 2. Rlpm_OCF & 0.6453 & 1 & 0.0084 & -0.1197 & -0.1627 & -0.0784 & -0.1125 & -0.1373 & -0.0806 & -0.0714 & -0.1545 & -0.1122 & -0.0286 & -0.0197 & -0.0194 \\
\hline 3. CFaR & 0.0531 & 0.1053 & 1 & 0.0114 & 0.0031 & 0.0034 & 0.0456 & -0.0017 & -0.0062 & 0.0098 & 0.0067 & 0.0124 & -0.0070 & 0.0012 & 0.0012 \\
\hline 4. $U C_{-} P C A$ & -0.0533 & -0.1226 & -0.1004 & 1 & 0.2044 & 0.9697 & 0.2090 & 0.1621 & 0.0978 & -0.0556 & 0.1360 & 0.0582 & $\mathbf{0 . 0 3 0 7}$ & 0.0727 & 0.0720 \\
\hline 5. $U C_{-} A C C$ & -0.0082 & -0.1611 & -0.0515 & 0.1973 & 1 & 0.0419 & 0.0950 & 0.4510 & 0.4192 & -0.0324 & 0.2705 & 0.1466 & 0.0171 & 0.0002 & 0.0000 \\
\hline 6. $U C_{-} B M$ & -0.0418 & -0.0799 & -0.0917 & 0.9787 & 0.0525 & 1 & 0.0136 & 0.0999 & 0.0296 & -0.0681 & 0.1037 & -0.0167 & 0.1234 & 0.0721 & 0.0715 \\
\hline 7. UC_RES & -0.1121 & -0.1690 & -0.0933 & 0.0841 & 0.0337 & -0.0148 & 1 & -0.0007 & 0.0429 & 0.0803 & -0.0185 & 0.2894 & -0.0385 & 0.0186 & 0.0181 \\
\hline 8. $C C_{-} P C A$ & -0.0155 & -0.1357 & -0.0016 & 0.1627 & 0.4675 & 0.0994 & -0.0092 & 1 & 0.7332 & -0.2474 & 0.7400 & -0.0044 & 0.0392 & -0.0050 & -0.0049 \\
\hline 9. $C C_{-} A C M$ & -0.0257 & -0.0817 & -0.0345 & 0.0955 & 0.4166 & 0.0277 & 0.0217 & 0.7282 & 1 & -0.0280 & 0.1314 & 0.0701 & 0.0224 & 0.0035 & 0.0038 \\
\hline 10. $C C_{-} A R A$ & -0.0661 & -0.0810 & 0.0864 & -0.0501 & -0.0476 & -0.0569 & 0.0637 & -0.2362 & -0.0300 & 1 & -0.0421 & -0.0162 & -0.0994 & -0.0191 & -0.0184 \\
\hline 11. $C C_{-} C R A$ & -0.0192 & -0.1550 & 0.0609 & 0.1368 & 0.2949 & 0.1025 & -0.0171 & 0.7351 & 0.1311 & -0.0421 & 1 & 0.3917 & 0.0285 & -0.0120 & -0.0119 \\
\hline 12. Cash & -0.0422 & -0.1096 & 0.0010 & 0.0402 & 0.1275 & -0.0259 & 0.3611 & 0.0170 & 0.0769 & 0.0957 & 0.0162 & 1 & -0.1012 & -0.0096 & -0.0096 \\
\hline 13. Hedger & -0.0262 & -0.0326 & -0.0325 & 0.0867 & 0.0527 & 0.1279 & -0.0329 & 0.0602 & 0.0223 & -0.0975 & 0.0455 & -0.1019 & 1 & 0.0278 & 0.0275 \\
\hline 14. Dcfbeta1 & -0.0153 & 0.0050 & 0.0026 & 0.1051 & -0.0479 & 0.1169 & -0.0310 & -0.0284 & -0.0418 & 0.0210 & -0.0017 & -0.0634 & 0.0155 & 1 & 0.9985 \\
\hline 15. Dcfbeta2 & -0.0183 & -0.0001 & 0.0007 & 0.1060 & -0.0534 & 0.1183 & -0.0284 & -0.0310 & -0.0473 & 0.0255 & 0.0007 & -0.0683 & 0.0108 & 0.9913 & 1 \\
\hline
\end{tabular}

Hedger is a dummy variable equal to 1 for firms with a hedger program and 0 otherwise. 


\section{Table 3 Logit Model Estimation Results for Relations between Unconditional and Conditional Conservatism and Indicator for OCF Downside Risk DOCF}

This table reports estimation results for logit model regressions of OCF downside risk indicator $D O C F$ on unconditional and conditional conservatism metrics UC_PCA, UC_ACC, UC_BM and UC_RES, and CC_PCA, CC_ACM, CC ARA and $C C_{-} C R A$. Model specifications and variable definitions are presented at the bottom of this table and Table 1 , respectively.

\begin{tabular}{|c|c|c|c|c|c|c|c|}
\hline Variables & Model 1 & Model 2 & Model 3 & Model 4 & Model 5 & Model 6 & Model 7 \\
\hline Intercept & $\begin{array}{l}0.8439 \\
(5.11)^{* * *}\end{array}$ & $\begin{array}{l}0.7818 \\
(4.75)^{* * *}\end{array}$ & $\begin{array}{l}0.8380 \\
(5.07)^{* * *}\end{array}$ & $\begin{array}{l}0.7853 \\
(4.78)^{* * *}\end{array}$ & $\begin{array}{l}0.7978 \\
(4.84)^{* * * *}\end{array}$ & $\begin{array}{l}0.8309 \\
(5.04)^{* * *}\end{array}$ & $\begin{array}{l}1.0104 \\
(5.91)^{* * *}\end{array}$ \\
\hline$U \boldsymbol{C}_{-} \boldsymbol{P} \boldsymbol{C A}_{i t-l}$ & $\begin{array}{l}-0.4341 \\
(-4.67)^{* * *}\end{array}$ & & \multirow{3}{*}{$\begin{array}{l}-0.1628 \\
(-2.82)^{* * *}\end{array}$} & \multirow{4}{*}{$\begin{array}{l}-0.1798 \\
(-3.13)^{* * *}\end{array}$} & $\begin{array}{l}-0.4418 \\
(-4.77)^{* * *}\end{array}$ & \multirow[t]{6}{*}{$\begin{array}{l}-0.4386 \\
(-4.73)^{* * *}\end{array}$} & \multirow[t]{7}{*}{$\begin{array}{l}-0.4604 \\
(-5.00)^{* * *}\end{array}$} \\
\hline$C C_{-} P C A_{i t-1}$ & $\begin{array}{l}-0.1436 \\
(-2.48)^{* * * *}\end{array}$ & $\begin{array}{l}-0.1858 \\
(-2.97)^{* * *}\end{array}$ & & & & & \\
\hline$U \boldsymbol{C}_{-} \boldsymbol{A} \boldsymbol{C} \boldsymbol{C}_{i t-I}$ & & $\begin{array}{l}0.1516 \\
(0.33)\end{array}$ & & & & & \\
\hline $\boldsymbol{U} \boldsymbol{C}_{-} \boldsymbol{B} \boldsymbol{M}_{i t-1}$ & & & $\begin{array}{l}-0.2542 \\
(-3.70) * * *\end{array}$ & & & & \\
\hline$U C_{-} \boldsymbol{R} E \boldsymbol{S}_{i t-1}$ & & & & $\begin{array}{l}-0.2924 \\
(-4.71)^{* * *}\end{array}$ & & & \\
\hline$C C_{-} \boldsymbol{A C M} \boldsymbol{M}_{i t-1}$ & & & & & $\begin{array}{l}-0.6279 \\
(-2.79)^{* * *}\end{array}$ & & \\
\hline $\boldsymbol{C} C_{-} \boldsymbol{A R} \boldsymbol{A}_{i t-l}$ & & & & & & $\begin{array}{l}-0.1620 \\
(-2.50) * * *\end{array}$ & \\
\hline $\boldsymbol{C C}_{-} \boldsymbol{C R} \boldsymbol{A}_{i t-1}$ & & & & & & & $\begin{array}{l}-0.3117 \\
(-4.38)^{* * *}\end{array}$ \\
\hline $\operatorname{Cash}_{i t-1}$ & $\begin{array}{l}-0.4279 \\
(-2.89)^{* * *}\end{array}$ & $\begin{array}{l}-0.4778 \\
(-3.21)^{* * *}\end{array}$ & $\begin{array}{l}-0.4550 \\
(-3.08)^{* * *}\end{array}$ & $\begin{array}{l}-0.4384 \\
(-2.96)^{* * *}\end{array}$ & $\begin{array}{l}-0.4156 \\
(-2.81)^{* * *}\end{array}$ & $\begin{array}{l}-0.4274 \\
(-2.89)^{* * *}\end{array}$ & $\begin{array}{l}-0.3977 \\
(-2.68)^{* * *}\end{array}$ \\
\hline$\Delta \operatorname{Cash}_{i t-1}$ & $\begin{array}{l}0.0088 \\
(0.59)\end{array}$ & $\begin{array}{l}0.0090 \\
(0.60)\end{array}$ & $\begin{array}{l}0.0090 \\
(0.60)\end{array}$ & $\begin{array}{l}0.0085 \\
(0.58)\end{array}$ & $\begin{array}{l}0.0090 \\
(0.60)\end{array}$ & $\begin{array}{l}0.0086 \\
(0.57)\end{array}$ & $\begin{array}{l}0.0092 \\
(0.60)\end{array}$ \\
\hline Invest_CAPX $X_{i t-1}$ & $\begin{array}{l}0.0264 \\
(0.45)\end{array}$ & $\begin{array}{l}0.0236 \\
(0.42)\end{array}$ & $\begin{array}{l}0.0258 \\
(0.44)\end{array}$ & $\begin{array}{l}0.0241 \\
(0.43)\end{array}$ & $\begin{array}{l}0.0255 \\
(0.44)\end{array}$ & $\begin{array}{l}0.0273 \\
(0.46)\end{array}$ & $\begin{array}{l}0.0293 \\
(0.48)\end{array}$ \\
\hline Invest_RD $D_{i t-I}$ & $\begin{array}{l}-7.6019 \\
(-17.90)^{* * *}\end{array}$ & $\begin{array}{l}-7.9860 \\
(-19.08)^{* * *}\end{array}$ & $\begin{array}{l}-7.8190 \\
(-18.62)^{* * *}\end{array}$ & $\begin{array}{l}-7.4107 \\
(-17.19) * * *\end{array}$ & $\begin{array}{l}-7.5873 \\
(-17.86)^{* * *}\end{array}$ & $\begin{array}{l}-7.6097 \\
(-17.93)^{* * *}\end{array}$ & $\begin{array}{l}-7.5250 \\
(-17.73)^{* * *}\end{array}$ \\
\hline Leverage $_{i t-I}$ & $\begin{array}{l}1.0252 \\
(7.48)^{* * *}\end{array}$ & $\begin{array}{l}1.0354 \\
(7.53)^{* * *}\end{array}$ & $\begin{array}{l}1.0341 \\
(7.55)^{* * *}\end{array}$ & $\begin{array}{l}1.0222 \\
(7.46)^{* * *}\end{array}$ & $\begin{array}{l}1.0083 \\
(7.37)^{* * *}\end{array}$ & $\begin{array}{l}1.0421 \\
(7.58)^{* * *}\end{array}$ & $\begin{array}{l}1.0564 \\
(7.71)^{* * *}\end{array}$ \\
\hline $\operatorname{Loss}_{i t-l}$ & $\begin{array}{l}-0.2077 \\
(-3.18)^{* * *}\end{array}$ & $\begin{array}{l}-0.2094 \\
(-3.20)^{* * *}\end{array}$ & $\begin{array}{l}-0.2077 \\
(-3.18)^{* * *}\end{array}$ & $\begin{array}{l}-0.2132 \\
(-3.26)^{* * *}\end{array}$ & $\begin{array}{l}-0.2070 \\
(-3.17)^{* * *}\end{array}$ & $\begin{array}{l}-0.2059 \\
(-3.15)^{* * *}\end{array}$ & $\begin{array}{l}-0.1846 \\
(-2.82)^{* * *}\end{array}$ \\
\hline $\boldsymbol{O} \boldsymbol{O}_{i t-1}$ & $\begin{array}{l}-0.3047 \\
(-4.96)^{* * *}\end{array}$ & $\begin{array}{l}-0.3191 \\
(-5.20)^{* * *}\end{array}$ & $\begin{array}{l}-0.3096 \\
(-5.05)^{* * *}\end{array}$ & $\begin{array}{l}-0.3170 \\
(-5.17)^{* * *}\end{array}$ & $\begin{array}{l}-0.3191 \\
(-5.23)^{* * *}\end{array}$ & $\begin{array}{l}-0.2973 \\
(-4.81)^{* * *}\end{array}$ & $\begin{array}{l}-0.3319 \\
(-5.44) * * *\end{array}$ \\
\hline $\boldsymbol{R} \boldsymbol{O} \boldsymbol{A}_{i t-1}$ & $\begin{array}{l}-4.1347 \\
(-14.76) * * *\end{array}$ & $\begin{array}{l}-4.2393 \\
(-14.87)^{* * *}\end{array}$ & $\begin{array}{l}-4.1139 \\
(-14.59) * * *\end{array}$ & $\begin{array}{l}-4.3205 \\
(-15.34)^{* * *}\end{array}$ & $\begin{array}{l}-4.1454 \\
(-14.79)^{* * *}\end{array}$ & $\begin{array}{l}-4.0992 \\
(-14.70)^{* * *}\end{array}$ & $\begin{array}{l}-3.9643 \\
(-14.25) * * *\end{array}$ \\
\hline $\operatorname{Sigma}_{i t-1}$ & $\begin{array}{l}-0.1768 \\
(-1.98)^{* *}\end{array}$ & $\begin{array}{l}-0.1834 \\
(-2.06)^{* *}\end{array}$ & $\begin{array}{l}-0.1803 \\
(-2.02)^{* *}\end{array}$ & $\begin{array}{l}-0.1738 \\
(-1.95)^{*}\end{array}$ & $\begin{array}{l}-0.1823 \\
(-2.04)^{* *}\end{array}$ & $\begin{array}{l}-0.1766 \\
(-1.98)^{* *}\end{array}$ & $\begin{array}{l}-0.1845 \\
(-2.07)^{* *}\end{array}$ \\
\hline Size $_{i t-1}$ & $\begin{array}{l}0.0547 \\
(4.65)^{* * *}\end{array}$ & $\begin{array}{l}0.0463 \\
(3.99)^{* * *}\end{array}$ & $\begin{array}{l}0.0533 \\
(4.53)^{* * *}\end{array}$ & $\begin{array}{l}0.0461 \\
(3.97)^{* * *}\end{array}$ & $\begin{array}{l}0.0520 \\
(4.47)^{* * *}\end{array}$ & $\begin{array}{l}0.0530 \\
(4.54)^{* * *}\end{array}$ & $\begin{array}{l}0.0372 \\
(3.10)^{* * *}\end{array}$ \\
\hline Slack $_{i t-1}$ & $\begin{array}{l}0.0021 \\
(0.13)\end{array}$ & $\begin{array}{l}0.0031 \\
(0.18)\end{array}$ & $\begin{array}{l}0.0024 \\
(0.15)\end{array}$ & $\begin{array}{l}0.0024 \\
(0.15)\end{array}$ & $\begin{array}{l}0.0040 \\
(0.21)\end{array}$ & $\begin{array}{l}0.0004 \\
(0.03)\end{array}$ & $\begin{array}{l}0.0005 \\
(0.03)\end{array}$ \\
\hline Slack_emp ${ }_{i t-l}$ & $\begin{array}{l}6.9642 \\
(4.92)^{* * *}\end{array}$ & $\begin{array}{l}6.8953 \\
(4.87)^{* * *}\end{array}$ & $\begin{array}{l}6.9756 \\
(4.93)^{* * *}\end{array}$ & $\begin{array}{l}6.8769 \\
(4.86)^{* * *}\end{array}$ & $\begin{array}{l}6.9346 \\
(4.89)^{* * *}\end{array}$ & $\begin{array}{l}6.9993 \\
(4.95)^{* * *}\end{array}$ & $\begin{array}{l}7.0369 \\
(4.98)^{* * *}\end{array}$ \\
\hline $\mathrm{CEO}_{-}$Delta $_{i t-1}$ & $\begin{array}{l}-1.8095 \\
(-3.97)^{* * *}\end{array}$ & $\begin{array}{l}-1.7047 \\
(-3.76)^{* * *}\end{array}$ & $\begin{array}{l}-1.7861 \\
(-3.92)^{* * *}\end{array}$ & $\begin{array}{l}-1.7106 \\
(-3.77)^{* * *}\end{array}$ & $\begin{array}{l}-1.8054 \\
(-3.97)^{* * *}\end{array}$ & $\begin{array}{l}-1.7947 \\
(-3.94)^{* * *}\end{array}$ & $\begin{array}{l}-1.7234 \\
(-3.78)^{* * *}\end{array}$ \\
\hline $\begin{array}{l}C E O_{-} \text {Vega } a_{i t-I} \\
\text { Ind.\& Year }\end{array}$ & $\begin{array}{l}-0.0084 \\
(-0.62)\end{array}$ & $\begin{array}{l}-0.0083 \\
(-0.61)\end{array}$ & $\begin{array}{l}-0.0083 \\
(-0.61)\end{array}$ & $\begin{array}{l}-0.0083 \\
(-0.61)\end{array}$ & $\begin{array}{l}-0.0089 \\
(-0.66)\end{array}$ & $\begin{array}{l}-0.0082 \\
(-0.61)\end{array}$ & $\begin{array}{l}-0.0089 \\
(-0.65)\end{array}$ \\
\hline Dummies & Yes & Yes & Yes & Yes & Yes & Yes & Yes \\
\hline Observations & 28,425 & 28,425 & 28,425 & 28,425 & 28,425 & 28,425 & 28,425 \\
\hline Psuedo R-square & 0.4858 & 0.4852 & 0.4856 & 0.4857 & 0.4859 & 0.4861 & 0.4858 \\
\hline
\end{tabular}

$*, * *$, and $* * *$ indicate that a coefficient is significant at $90 \%, 95 \%$, and $99 \%$ confidence level, respectively.

The logit model used in this table is: $D O C F_{i t}=\alpha+\gamma C O N_{i t-1}+$ Controls $_{i t-1}+\mu_{i t-1}$

where $C O N=U C_{-} P C A, C C_{-} P C A, U C_{-} A C C, U C \_B M, U C \_R E S, C C \_A C M, C C \_A R A$, or CC_CRA, for Models 1 to 7. Controls include Cash, $\triangle$ Cash, Invest_CAPX, Invest_RD, Leverage, Loss, OO, ROA, Sigma, Size, Slack, Slack_emp, CEO_Delta, CEO_Vega, Ind and Year dummies. 
Table 4 Fama-Macbeth Regression Estimation Results for Relations between Unconditional and Conditional Conservatism and OCF Downside Risk Rlpm OCF

This table reports estimation results for the Fama-MacBeth regressions of OCF downside risk measure Rlpm_OCF on lagged unconditional and conditional conservatism metrics $U C_{-} P C A, U C_{-} A C C, U C_{-} B M$ and $U C_{-} R E \bar{S}$, and $C C_{-} P C A, C C_{-} A C M, C C_{-} A R A$ and $C_{-} C R A$, respectively, as well as other control variables. $T$-statistics are corrected for heteroscedasticity and first-order autocorrelations using the Newey-West procedure. Model specifications and variable definitions are presented at the bottom of this table and Table 1.

\begin{tabular}{|c|c|c|c|c|c|c|c|}
\hline Variables & Model 1 & Model 2 & Model 3 & Model 4 & Model 5 & Model 6 & Model 7 \\
\hline Intercept & $\begin{array}{l}0.7760 \\
(41.71)^{* * *}\end{array}$ & $\begin{array}{l}0.7679 \\
(42.85)^{* * *}\end{array}$ & $\begin{array}{l}0.7752 \\
(41.6)^{* * *}\end{array}$ & $\begin{array}{l}0.7755 \\
(43.85)^{* * *}\end{array}$ & $\begin{array}{l}0.7694 \\
(43.84)^{* * *}\end{array}$ & $\begin{array}{l}0.7713 \\
(43.25)^{* * *}\end{array}$ & $\begin{array}{l}0.7774 \\
(39.9)^{* * *}\end{array}$ \\
\hline $\boldsymbol{U} \boldsymbol{C}_{-} \boldsymbol{P} \boldsymbol{C A}_{i t-1}$ & $\begin{array}{l}-0.0137 \\
(-1.75)^{*}\end{array}$ & & & & $\begin{array}{l}-0.0220 \\
(-2.68)^{* * *}\end{array}$ & $\begin{array}{l}-0.0241 \\
(-2.85)^{* * *}\end{array}$ & $\begin{array}{l}-0.0132 \\
(-1.61)\end{array}$ \\
\hline$C C_{-} P C A_{i t-1}$ & $\begin{array}{l}-0.0587 \\
(-17.06)^{* * *}\end{array}$ & $\begin{array}{l}-0.0486 \\
(-10.85)^{* * *}\end{array}$ & $\begin{array}{l}-0.0595 \\
(-16.67)^{* * *}\end{array}$ & $\begin{array}{l}-0.0600 \\
(-15.41)^{* * *}\end{array}$ & & & \\
\hline $\boldsymbol{U} \boldsymbol{C}_{-} \boldsymbol{A} \boldsymbol{C} \boldsymbol{C}_{i t-1}$ & & $\begin{array}{l}-0.1911 \\
(-3.58) * * *\end{array}$ & & & & & \\
\hline $\boldsymbol{U} \boldsymbol{C}_{-} \boldsymbol{B} \boldsymbol{M}_{i t-1}$ & & & $\begin{array}{l}-0.0044 \\
(-0.76)\end{array}$ & & & & \\
\hline$U C_{-} \boldsymbol{R} E S_{i t-1}$ & & & & $\begin{array}{l}-0.0305 \\
(-2.83)^{* * *}\end{array}$ & & & \\
\hline$C C_{-} A C M_{i t-I}$ & & & & & $\begin{array}{l}-0.0221 \\
(-6.29) * * *\end{array}$ & & \\
\hline$C_{-} \boldsymbol{A R}_{i t-1}$ & & & & & & $\begin{array}{l}-0.0150 \\
(-4.44) * * *\end{array}$ & \\
\hline$C_{-} C_{-} \boldsymbol{R} A_{i t-1}$ & & & & & & & $\begin{array}{l}-0.0812 \\
(-14.95) * * *\end{array}$ \\
\hline $\operatorname{Cash}_{i t-1}$ & $\begin{array}{l}-0.0562 \\
(-4.47)^{* * *}\end{array}$ & $\begin{array}{l}-0.0495 \\
(-4.06)^{* * *}\end{array}$ & $\begin{array}{l}-0.0574 \\
(-4.51)^{* * *}\end{array}$ & $\begin{array}{l}-0.0557 \\
(-4.16)^{* * *}\end{array}$ & $\begin{array}{l}-0.0585 \\
(-4.33)^{* * *}\end{array}$ & $\begin{array}{l}-0.0581 \\
(-4.29)^{* * *}\end{array}$ & $\begin{array}{l}-0.0561 \\
(-4.69)^{* * *}\end{array}$ \\
\hline$\Delta$ Cash $_{i t-1}$ & $\begin{array}{l}0.0008 \\
(0.11)\end{array}$ & $\begin{array}{l}0.0012 \\
(0.17)\end{array}$ & $\begin{array}{l}0.0008 \\
(0.12)\end{array}$ & $\begin{array}{l}-0.0002 \\
(-0.02)\end{array}$ & $\begin{array}{l}-0.0052 \\
(-0.77)\end{array}$ & $\begin{array}{l}-0.0058 \\
(-0.87)\end{array}$ & $\begin{array}{l}0.0048 \\
(0.7)\end{array}$ \\
\hline Invest_CAPX $X_{i t-1}$ & $\begin{array}{l}0.0066 \\
(0.28)\end{array}$ & $\begin{array}{l}0.0032 \\
(0.14)\end{array}$ & $\begin{array}{l}0.0052 \\
(0.22)\end{array}$ & $\begin{array}{l}0.0023 \\
(0.09)\end{array}$ & $\begin{array}{l}-0.0042 \\
(-0.17)\end{array}$ & $\begin{array}{l}-0.0051 \\
(-0.21)\end{array}$ & $\begin{array}{l}0.0081 \\
(0.35)\end{array}$ \\
\hline Invest_RD $D_{i t-I}$ & $\begin{array}{l}-0.7066 \\
(-24.06)^{* * *}\end{array}$ & $\begin{array}{l}-0.7187 \\
(-23.14)^{* * *}\end{array}$ & $\begin{array}{l}-0.7160 \\
(-23.5)^{* * *}\end{array}$ & $\begin{array}{l}-0.6605 \\
(-21.34)^{* * *}\end{array}$ & $\begin{array}{l}-0.6964 \\
(-22.63)^{* * *}\end{array}$ & $\begin{array}{l}-0.6928 \\
(-21.69)^{* * *}\end{array}$ & $\begin{array}{l}-0.7094 \\
(-23.91)^{* * *}\end{array}$ \\
\hline Leverage $_{i t-1}$ & $\begin{array}{l}0.0642 \\
(13.94)^{* * *}\end{array}$ & $\begin{array}{l}0.0606 \\
(13.43)^{* * *}\end{array}$ & $\begin{array}{l}0.0644 \\
(14.05)^{* * *}\end{array}$ & $\begin{array}{l}0.0625 \\
(13.5)^{* * *}\end{array}$ & $\begin{array}{l}0.0574 \\
(12.61)^{* * *}\end{array}$ & $\begin{array}{l}0.0576 \\
(14.99)^{* * *}\end{array}$ & $\begin{array}{l}0.0712 \\
(17.39)^{* * *}\end{array}$ \\
\hline $\operatorname{Loss}_{i t-1}$ & $\begin{array}{l}-0.0102 \\
(-1.83)^{*}\end{array}$ & $\begin{array}{l}-0.0095 \\
(-1.76)^{*}\end{array}$ & $\begin{array}{l}-0.0103 \\
(-1.84)^{*}\end{array}$ & $\begin{array}{l}-0.0111 \\
(-2.01)^{* *}\end{array}$ & $\begin{array}{l}-0.0109 \\
(-1.98)^{* *}\end{array}$ & $\begin{array}{l}-0.0103 \\
(-1.88)^{*}\end{array}$ & $\begin{array}{l}-0.0081 \\
(-1.66)^{*}\end{array}$ \\
\hline $\boldsymbol{O O}_{i t-1}$ & $\begin{array}{l}-0.0203 \\
(-2.28)^{* *}\end{array}$ & $\begin{array}{l}-0.0182 \\
(-2.37)^{* *}\end{array}$ & $\begin{array}{l}-0.0204 \\
(-2.29)^{* *}\end{array}$ & $\begin{array}{l}-0.0201 \\
(-2.30)^{* *}\end{array}$ & $\begin{array}{l}-0.0266 \\
(-2.80)^{* * *}\end{array}$ & $\begin{array}{l}-0.0275 \\
(-2.87)^{* * *}\end{array}$ & $\begin{array}{l}-0.0166 \\
(-1.95)^{*}\end{array}$ \\
\hline $\boldsymbol{R} \boldsymbol{O} \boldsymbol{A}_{i t-1}$ & $\begin{array}{l}-0.4341 \\
(-19.46)^{* * *}\end{array}$ & $\begin{array}{l}-0.4565 \\
(-17.02)^{* * *}\end{array}$ & $\begin{array}{l}-0.4347 \\
(-20.22)^{* * *}\end{array}$ & $\begin{array}{l}-0.4454 \\
(-18.96)^{* * *}\end{array}$ & $\begin{array}{l}-0.4158 \\
(-20.45)^{* * *}\end{array}$ & $\begin{array}{l}-0.4061 \\
(-19.48)^{* * *}\end{array}$ & $\begin{array}{l}-0.4258 \\
(-19.01)^{* * *}\end{array}$ \\
\hline Sigma $_{i t-1}$ & $\begin{array}{l}-0.0174 \\
(-2.41)^{* *}\end{array}$ & $\begin{array}{l}-0.0186 \\
(-2.50)^{* *}\end{array}$ & $\begin{array}{l}-0.0177 \\
(-2.43)^{* *}\end{array}$ & $\begin{array}{l}-0.0175 \\
(-2.36)^{* *}\end{array}$ & $\begin{array}{l}-0.0186 \\
(-2.46)^{* *}\end{array}$ & $\begin{array}{l}-0.0190 \\
(-2.57)^{* *}\end{array}$ & $\begin{array}{l}-0.0183 \\
(-2.75)^{* * *}\end{array}$ \\
\hline Size $_{i t-1}$ & $\begin{array}{l}0.0039 \\
(2.68)^{* * *}\end{array}$ & $\begin{array}{l}0.0038 \\
(2.48)^{* *}\end{array}$ & $\begin{array}{l}0.0038 \\
(2.60)^{* * *}\end{array}$ & $\begin{array}{l}0.0038 \\
(2.44)^{* *}\end{array}$ & $\begin{array}{l}0.0024 \\
(1.51)\end{array}$ & $\begin{array}{l}0.0015 \\
(0.92)\end{array}$ & $\begin{array}{l}0.0035 \\
(2.28)^{* *}\end{array}$ \\
\hline Slack $_{i t-1}$ & $\begin{array}{l}-0.0038 \\
(-1.36)\end{array}$ & $\begin{array}{l}-0.0053 \\
(-1.61)\end{array}$ & $\begin{array}{l}-0.0036 \\
(-1.28)\end{array}$ & $\begin{array}{l}-0.0026 \\
(-0.83)\end{array}$ & $\begin{array}{l}-0.0048 \\
(-1.76)^{*}\end{array}$ & $\begin{array}{l}-0.0066 \\
(-2.27)^{* *}\end{array}$ & $\begin{array}{l}-0.0083 \\
(-2.40)^{* *}\end{array}$ \\
\hline Slack_emp $p_{i t-1}$ & $\begin{array}{l}0.2681 \\
(3.16)^{* * *}\end{array}$ & $\begin{array}{l}0.2580 \\
(3.18)^{* * *}\end{array}$ & $\begin{array}{l}0.2680 \\
(3.16)^{* * *}\end{array}$ & $\begin{array}{l}0.2729 \\
(3.27)^{* * *}\end{array}$ & $\begin{array}{l}0.3009 \\
(3.15)^{* * *}\end{array}$ & $\begin{array}{l}0.3080 \\
(3.14)^{* * *}\end{array}$ & $\begin{array}{l}0.2625 \\
(3.17)^{* * *}\end{array}$ \\
\hline CEO_Delta ${ }_{i t-1}$ & $\begin{array}{l}-0.0986 \\
(-6.20)^{* * *}\end{array}$ & $\begin{array}{l}-0.0985 \\
(-6.22)^{* * *}\end{array}$ & $\begin{array}{l}-0.0974 \\
(-6.14)^{* * *}\end{array}$ & $\begin{array}{l}-0.0965 \\
(-6.26)^{* * *}\end{array}$ & $\begin{array}{l}-0.1011 \\
(-6.81)^{* * *}\end{array}$ & $\begin{array}{l}-0.1015 \\
(-6.44)^{* * *}\end{array}$ & $\begin{array}{l}-0.0973 \\
(-6.22)^{* * *}\end{array}$ \\
\hline CEO_Vega $a_{i t-1}$ & $\begin{array}{l}-0.0178 \\
(-0.96)\end{array}$ & $\begin{array}{l}-0.0170 \\
(-0.95)\end{array}$ & $\begin{array}{l}-0.0178 \\
(-0.96)\end{array}$ & $\begin{array}{l}-0.0174 \\
(-0.96)\end{array}$ & $\begin{array}{l}-0.0185 \\
(-0.97)\end{array}$ & $\begin{array}{l}-0.0174 \\
(-0.97)\end{array}$ & $\begin{array}{l}-0.0169 \\
(-0.96)\end{array}$ \\
\hline Ind. Dummies & Yes & Yes & Yes & Yes & Yes & Yes & Yes \\
\hline $\begin{array}{l}\text { Observations } \\
\text { R-square }\end{array}$ & $\begin{array}{l}28,425 \\
0.7940 \\
\end{array}$ & $\begin{array}{l}28,425 \\
0.7943 \\
\end{array}$ & $\begin{array}{l}28,425 \\
0.7940 \\
\end{array}$ & $\begin{array}{l}28,425 \\
0.7937 \\
\end{array}$ & $\begin{array}{l}28,425 \\
0.7906 \\
\end{array}$ & $\begin{array}{l}28,425 \\
0.7903 \\
\end{array}$ & $\begin{array}{l}28,425 \\
0.7960 \\
\end{array}$ \\
\hline
\end{tabular}

$*, * *$, and $* * *$ indicate that a coefficient is significant at $90 \%, 95 \%$, and $99 \%$ confidence level, respectively.

The Fama-Macbeth regression used in this table is: Rlpm_OCF $F_{i t}=\alpha+\gamma$ CON $_{i t-1}+$ Controls $_{i t-1}+\mu_{i t-1}$

where $C O N=U C_{-} P C A, C C_{-} P C A, U C_{-} A C C, U C_{-} B \bar{M}, U C_{-} R E S, C C_{-} A C M, C C_{-} A R A$, or $C C_{-} C R A$ from Models 1 to 7 , respectively. Controls include Cash, $\triangle$ Cash, Invest_CAPX, Invest_RD, Leverage, Loss, OO, ROA, Sigma, Size, Slack, Slack_emp, CEO_Delta, CEO_Vega, Ind and Year dummies. 
Table 5 Fama-Macbeth Regression Estimation Results for Relations between Unconditional and Conditional Conservatism and OCF Downside Risk CFaR

This table reports estimation results for Fama-MacBeth regressions of future operational cash flow at risk $C F a R$ on lagged UC and CC metrics UC_PCA, UC_ACC, UC_BM and UC_RES, and CC_PCA, CC_ACM, $C C \_A R A$ and $C C_{-} C R A$, respectively, and other control variables. $T$-statistics are corrected for heteroscedasticity and first-order autocorrelation using the Newey-West procedure. Model specification details and variable definitions are presented at the bottom of this table and Table 1, respectively.



$*, * *$, and $* * *$ indicate that a coefficient is significant at $90 \%, 95 \%$, and $99 \%$ confidence level, respectively.

The Fama-Macbeth regression used in this table is: $C_{F a R_{i t}}=\alpha+\gamma C O N_{i t-1}+$ Controls $_{i t-1}+\mu_{i t-1}$, where $C O N=U C P C A, C C P C A, U C A C C, U C B M, U C R E S, C C A C M, C C A R A$, or $C C C R A$ from Models 1 to 7 , respectively. Controls include Cash, $\triangle \bar{C}$ ash, Invest_CAPX, Invest_RD, Leverage, Loss, OO, ROA, Sigma, Size, Slack, Slack_emp, CEO_Delta, CEO_Vega, Ind and Year dümmies. 


\section{Table 6 Cash and Relations between Unconditional and Conditional Conservatism and OCF Downside Risk Estimated by 3SLS Models}

This table reports estimation results for 3SLS regressions for relations between unconditional and conditional conservatism UC_PCA and CC_PCA, cash holdings Cash, and OCF downside risk Rlpm_OCF. Model specifications are provided at the bottom of the table and variable definitions are presented at Table 1.






\begin{tabular}{|c|c|c|c|c|c|c|c|c|}
\hline \multirow[t]{2}{*}{ Slack $_{i t-1}$} & & & 0.0009 & 0.0004 & & & -0.0089 & -0.0006 \\
\hline & & & $(2.66)^{* * *}$ & $(0.73)$ & & & $(-13.10)^{* * *}$ & $(-0.57)$ \\
\hline \multirow[t]{2}{*}{ Slack_emp $p_{i t-1}$} & & & 0.0033 & -0.0016 & & & 0.0004 & 0.0073 \\
\hline & & & $(0.77)$ & $(-0.31)$ & & & $(1.14)$ & $(0.36)$ \\
\hline \multirow[t]{2}{*}{ CEO_Delta ${ }_{i t-1}$} & -0.0328 & -0.0632 & 0.1043 & -0.1230 & -0.0308 & -0.0732 & 0.0033 & -0.2170 \\
\hline & $(-1.59)$ & $(-1.25)$ & $(5.07)^{* * *}$ & $(-5.03)^{* * *}$ & $(-1.19)$ & $(-1.20)$ & $(0.88)$ & $(-6.79)^{* * *}$ \\
\hline \multirow[t]{2}{*}{ CEO_Vega $a_{t-1}$} & -0.0008 & -0.0020 & -0.0009 & -0.0011 & -0.0003 & -0.0004 & 0.1390 & 0.0032 \\
\hline & $(-1.25)$ & $(-1.22)$ & $(-1.31)$ & $(-1.45)$ & $(-0.33)$ & $(-0.16)$ & $(6.14)^{* * *}$ & $(2.58)^{* * *}$ \\
\hline Ind. Dummies & Yes & Yes & Yes & Yes & Yes & Yes & Yes & Yes \\
\hline Observations & 27,566 & 27,566 & 22,112 & 22,112 & 15,360 & 15,360 & 12,393 & 12,393 \\
\hline R-square & 0.6647 & 0.1191 & 0.3399 & 0.7766 & 0.6554 & 0.1142 & 0.2872 & 0.7702 \\
\hline
\end{tabular}

$*, * *$, and $* * *$ indicate that a coefficient is significant at $90 \%, 95 \%$, and $99 \%$ confidence level, respectively.

The 3SLS model consists of the following three equations. The first-stage regression model is:

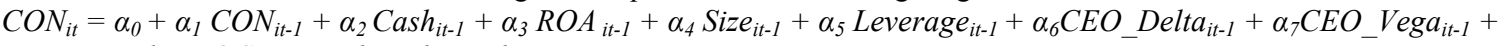

$$
\alpha_{8} R l p m_{-} O C F_{i t-1}+\Sigma b_{m} I_{n d}+\Sigma b_{n} \text { Year }_{n}+v_{i t-1} \text {, }
$$

where $\mathrm{CON}=\bar{U} C_{-} P C A$ or $C C_{-} P C A$. Residuals from this first-stage regression, $U C_{-} P C A_{-} R$ and $C C_{-} P C A_{-} R$ are used in the second and third-stage regressions.

The second-stage regression model is:

Cash $_{i t}=b_{0}+b_{1} U C_{-} P C A_{-} R_{i t-1}+b_{2} C C_{-} P C A_{-} R_{i t-1}+{\text { Controls } 11_{i t}}+\varepsilon_{i t}$,

where Controls1 includes lagged Cash, Dissue, DIV, Leverage, Loss, NWC, OO, ROA, Sigma, Size, Slack, Slack emp, CEO_Delta, CEO_Vega, Year and Ind. dummies.

The third-stage regression model is:

$R l p m \_O C F_{i t}=\gamma_{0}+\gamma_{1} C a s h \_R_{i t-1} * U C \_P C A \_R_{i t-1}+\gamma_{2} C a s h \_R_{i t-1} * C C \_P C A \_R_{i t-1}+\gamma_{3} U C_{-} P C A A_{i t-1}+\gamma_{4} C C_{-} P C A \_R_{i t-1}$ $+\gamma_{5}$ Cash $R_{i t-1}+$ Controls $2_{i t-1}+\mu_{i t}$

where Cash_R refers to residual for Cash from the second-stage. Controls 2 are the same as in Model (7). 
Table 7 Hedging and Relations between Unconditional and Conditional Conservatism and OCF Downside Risk Estimated by Extended Three-Stage Heckman Models

This table reports estimation results for the three-stage Heckman models for the effects of hedging usage on the relations of OCF downside risk proxied by Rlpm_OCF with unconditional and conditional conservatism UC_PCA and $C_{-} P C A$. Model specifications are provided at the bottom of the table and variable definitions are presented at the bottom of Tables 1 and 2 .

\begin{tabular}{|c|c|c|c|c|}
\hline \multirow{2}{*}{$\begin{array}{l}\text { Independent } \\
\text { Variables }\end{array}$} & \multicolumn{4}{|c|}{ Extended Three-Stage Heckman Model } \\
\hline & $1^{\text {st }}$-stage UC Model & $1^{\text {st }}$-stage CC Model & $\begin{array}{l}2^{\text {nd }}-\text { Stage Probit } \\
\text { Model for Hedger }\end{array}$ & $\begin{array}{c}3^{\text {rd }} \text {-Stage Model } \\
\text { for Rlpm_OCF }\end{array}$ \\
\hline Intercept & $\begin{array}{l}0.0747 \\
(9.86)^{* * *}\end{array}$ & $\begin{array}{l}0.4794 \\
(26.24)^{* * * *}\end{array}$ & $\begin{array}{l}-1.3732 \\
(-14.16) * * *\end{array}$ & 0.6147 \\
\hline $\boldsymbol{U} \boldsymbol{C}_{-} \boldsymbol{P C A _ { i t - 1 }}$ & $\begin{array}{l}0.7234 \\
(152.55)^{* * *}\end{array}$ & & & \\
\hline$C C_{-} P C A_{i t-1}$ & & $\begin{array}{l}0.1596 \\
(20.23)^{* * *}\end{array}$ & & \\
\hline $\boldsymbol{U} C_{-} P C A_{-} \boldsymbol{R}_{i t-1}$ & & & $\begin{array}{l}-0.1587 \\
(-1.64)^{*}\end{array}$ & $\begin{array}{l}-0.0120 \\
(-0.98)\end{array}$ \\
\hline$C C_{-} P C A \_R_{i t-1}$ & & & $\begin{array}{l}0.0705 \\
(1.77)^{*}\end{array}$ & $\begin{array}{l}-0.0465 \\
(-9.40)^{* * *}\end{array}$ \\
\hline Hedger & $\begin{array}{l}0.0170 \\
(7.20)^{* * *}\end{array}$ & $\begin{array}{l}0.0110 \\
(1.98)^{* *}\end{array}$ & & \\
\hline Hedger*post & & & & $\begin{array}{l}-0.1040 \\
(-6.02)^{* * *}\end{array}$ \\
\hline Post & & & & $\begin{array}{l}0.1035 \\
(5.68)^{* * *}\end{array}$ \\
\hline $\begin{array}{l}\text { UC_PCA_R } R_{i t-1} * \text { Hedger } \\
* \text { post } \\
\text { CC_PCA_R }{ }_{i t-1} * H e d g e r \\
* \text { post }\end{array}$ & & & & $\begin{array}{l}\mathbf{0 . 0 5 7 7} \\
(2.34) * * \\
0.0062 \\
(0.67) \\
\end{array}$ \\
\hline Rlpm_OCF $F_{t-1}$ & $\begin{array}{l}-0.0612 \\
(-14.94)^{* * *}\end{array}$ & $\begin{array}{l}-0.2712 \\
(-27.53)^{* * *}\end{array}$ & & \\
\hline$I N T_{-} B D_{i t-1}$ & & & $\begin{array}{l}0.0041 \\
(1.21)\end{array}$ & \\
\hline $\begin{array}{l}\text { Invest_RD }{ }_{i t-} \\
{ }_{1}^{*} \text { Leverage }_{i t-1}\end{array}$ & & & 3.9362 & \\
\hline $\boldsymbol{N O L _ { i t - 1 }}$ & & & \begin{tabular}{|l}
$(2.11)^{* *}$ \\
0.0045 \\
$(0.10)$
\end{tabular} & \\
\hline $\boldsymbol{B} \boldsymbol{A} \boldsymbol{S}_{i t-1}$ & & & $\begin{array}{l}-10.1451 \\
(-11.96)^{* * *}\end{array}$ & \\
\hline Cash $_{i t-1}$ & & & & $\begin{array}{l}-0.0573 \\
(-5.57)^{* * *}\end{array}$ \\
\hline$\Delta \operatorname{Cash}_{i t-1}$ & & & & $\begin{array}{l}-0.0025 \\
(-1.34)\end{array}$ \\
\hline Invest_CAPX $\boldsymbol{X}_{i t-1}$ & & & & $\begin{array}{l}0.0021 \\
(1.04)\end{array}$ \\
\hline Invest_RD $D_{i t-1}$ & & & $\begin{array}{l}-0.4089 \\
(-1.23)\end{array}$ & $\begin{array}{l}-0.7206 \\
(-24.11)^{* * *}\end{array}$ \\
\hline Leverage $_{i t-1}$ & $\begin{array}{l}0.0064 \\
(0.90)\end{array}$ & $\begin{array}{l}0.2454 \\
(14.54)^{* * * *}\end{array}$ & $\begin{array}{l}0.6895 \\
(7.35)^{* * *}\end{array}$ & $\begin{array}{l}0.0509 \\
(5.30)^{* * *}\end{array}$ \\
\hline $\operatorname{Loss}_{i t-1}$ & & & & $\begin{array}{l}-0.0114 \\
(-2.46)^{* *}\end{array}$ \\
\hline $\boldsymbol{O O \boldsymbol { O } _ { i t - 1 }}$ & & & & -0.0108 \\
\hline
\end{tabular}




\begin{tabular}{|c|c|c|c|c|}
\hline \multirow{3}{*}{$\boldsymbol{R O} \boldsymbol{A}_{i t-1}$} & & & & $(-2.61)^{* *}$ \\
\hline & -0.1065 & -0.3328 & 1.4424 & -0.0428 \\
\hline & $(-9.09)^{* * *}$ & $(-11.79)^{* *}$ & $(8.31)^{* * *}$ & $(-21.61)^{* * *}$ \\
\hline $\operatorname{Sigma}_{i t-1}$ & & & -0.0848 & -0.0125 \\
\hline \multirow[t]{2}{*}{ Size $_{i t-1}$} & 0.0048 & 0.0272 & $\begin{array}{l}(-1.32) \\
0.0441\end{array}$ & $\begin{array}{l}(-1.94)^{*} \\
0.0086\end{array}$ \\
\hline & $(8.29)^{* * *}$ & $(19.75)^{* * *}$ & $(5.47)^{* * *}$ & $(9.07) * * *$ \\
\hline Slack $_{i t-1}$ & & & & $\begin{array}{l}0.0003 \\
(0.51)\end{array}$ \\
\hline Slack_emp $p_{t-1}$ & & & & 0.0071 \\
\hline \multirow[t]{2}{*}{ CEO_Delta ${ }_{i t-1}$} & 0.0256 & -0.1087 & -1.7097 & $\mid \begin{array}{l}(0.85) \\
-0.1948\end{array}$ \\
\hline & $(0.92)$ & $(-1.65)^{*}$ & $(-4.82) * * *$ & $(-5.74)^{* * * *}$ \\
\hline \multirow[t]{2}{*}{ CEO_Vega ${ }_{i t-1}$} & 0.0028 & -0.0021 & 0.0446 & 0.0038 \\
\hline & $(1.85)^{*}$ & $(-0.57)$ & $(2.50) * *$ & $(1.98) * *$ \\
\hline \multirow[t]{2}{*}{ Mills } & & & & 0.0722 \\
\hline & & & & $(6.89) * * *$ \\
\hline Ind. Dummies & Yes & Yes & Yes & Yes \\
\hline $\begin{array}{l}\text { Observations } \\
\text { Pseudo R_square }\end{array}$ & 16,250 & 16,250 & $\begin{array}{l}13,391 \\
0.1054\end{array}$ & 12,068 \\
\hline R_square & 0.6657 & 0.1441 & & 0.7772 \\
\hline
\end{tabular}

$*, * *$, and $* * *$ indicate that a coefficient is significant at $90 \%, 95 \%$, and $99 \%$ confidence level, respectively.

The three-stage Heckman model used in this table consists of the following three equations.

The first-stage OLS model is:

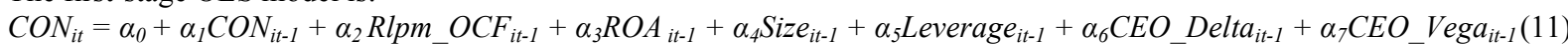
$+\alpha_{8}$ Hedger $_{i}+\Sigma b_{m}$ Ind $_{m}+\bar{\Sigma} b_{n}$ Year $_{n}+v_{i t-1}$

where $\mathrm{CON}=U C_{-} P C A$ or $C C_{-} P C A$. Residuals from this first-stage regression, $U C P C A \_R$ and $C C_{-} P C A \_$, are used in the second and third-stage regressions:

The second-stage probit model is:

Hedger $=b_{0}+b_{1} U C_{-} P C A_{-} R_{i t-1}+b_{2} C C_{-} P C A_{-} R_{i t-1}+$ Controls $3_{i t}+\varepsilon_{i t}$,

where Controls 3 include $I N T \_B D$, Invest_RD, Leverage, Invest_RD*Leverage, NOL, ROA, Sigma, Size, BAS, CEO_Delta, CEO_Vega, Ind and Year.

The third-stage difference-in-differences OLS model is:

$R l p m \_O C F_{i t}=\gamma_{0}+\gamma_{1} U C \_P C A \_R_{i t-1} * H_{e}$ Hedger ${ }_{i}^{*}$ Post $+\gamma_{2} C C_{-} P C A R_{i t-1} * \operatorname{Hedger}_{i}{ }^{*}$ Post $+\gamma_{3} U C_{-} P C A R_{i t-1}+$ $\gamma_{4} C C_{-} P C A_{-} R_{i t-1}+\gamma_{5} H_{\text {Hedger }}{ }^{*}$ Post $+\gamma_{6}$ Post $_{i}+\gamma_{7}$ Mills $_{i t-1}+$ Controls $_{i t-1}+\mu_{i t}$,

where Mills refers to the inverse Mills ratio calculated from the second-stage probit model, and Controls 4 refers to other control variables as in Model (7). POST is a dummy variable equal to one for the first and second year after initiating the hedging program, and zero otherwise. The third-stage OLS Model uses observations prior to initiating a hedging program and observations of non-hedging firms as the control sample. 
Table 8 Downside Cash Flow Beta and Relations between Unconditional and Conditional Conservatism and OCF Downside Risk Estimated by 3SLS Models

This table reports estimation results for the last stage of 3SLS models that regresses Rlpm_OCF against the interactions of downside cash flow beta and unconditional or conditional conservatism and other control variables. Downside cash flow beta is represented by Dcfbetal and Dcfbeta2. 3SLS model specifications are provided at the bottom of the table and variable definitions are presented at the bottom of Table 1 .

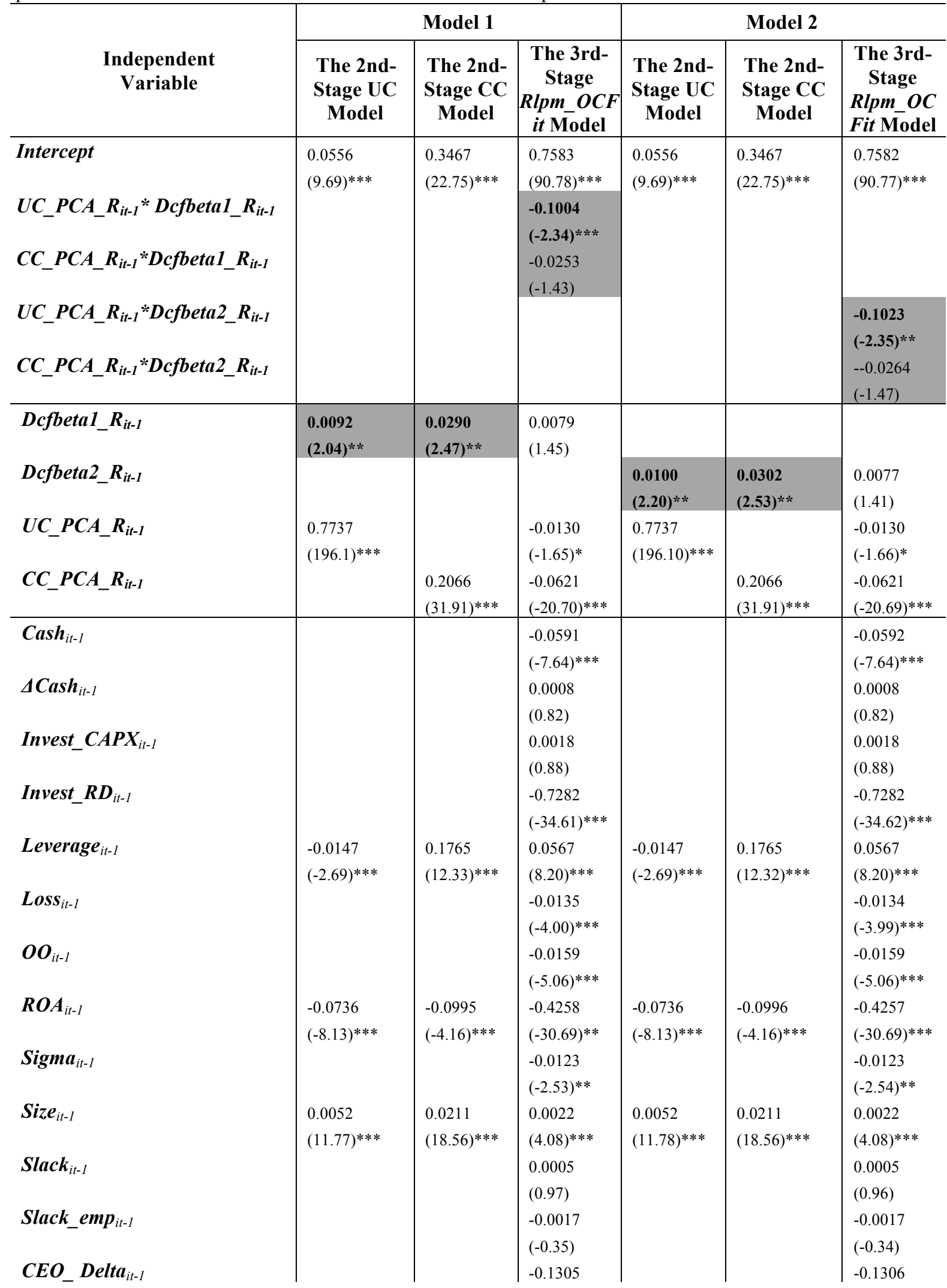




\begin{tabular}{l|l|l|l|l|l|l} 
& & & $(-5.57)^{* * *}$ & & & \\
CEO_Vega & & & -0.0012 & & & \\
& & & $(-5.57)^{* * *}$ & -0.0011 \\
& & & & & & \\
Ind. Dummies & Yes & Yes & Yes & & & Yes \\
\hline Observations & 23,438 & 23,438 & 22,004 & 23,438 & 23,438 & 22,003 \\
R-square & 0.6867 & 0.1002 & 0.7765 & 0.6874 & 0.1002 & 0.7800 \\
\hline
\end{tabular}

$*, * *$, and $* * *$ indicate that a coefficient is significant at $90 \%, 95 \%$, and $99 \%$ confidence level, respectively.

The 3SLS models used in this table are as follows. The first-stage OLS model is:

Shock $_{i t}=\gamma_{0}+\gamma_{1} U_{-} P C A_{i t-1}+\gamma_{2} C C_{-} P C A_{i t-1}+\gamma_{2}$ SIZE $_{i t-1}+\gamma_{3}$ Leverage $_{i t-1}+\gamma_{4} R O A_{i t-1}+\gamma_{5}$ Shock $_{i t-1}+\gamma_{6}$ CEO_Delta $i t-1$

$+\gamma_{7} C E O \operatorname{Vega}_{i t-1}+\Sigma b_{m}$ Ind $_{m}+\Sigma b_{n} \overline{Y e a r}_{n}+\mu_{i t}$

where $C O N=U C_{-} P C A$ and $C C_{-} P C A$, Shock $=$ Dcfbetal and Dcfbeta2. The estimated residuals from this stage, Shock_R, are used in the later stage regressions.

The second-stage OLS regressions model is:

$\operatorname{CON}_{i t}=\alpha_{0}+\alpha_{1} \operatorname{CON}_{i t-1}+\alpha_{2}$ SIZE $_{i t-1}+\alpha_{3}$ Leverage $_{i t-1}+\alpha_{4}$ ROA $_{i t-1}+\alpha_{5}$ Shock $_{i t-1}+\alpha_{6}$ CEO_Delta $i t-1$

$$
+\alpha_{7} \text { CEO Vega } a_{i t-1}+\Sigma b_{m} \text { Ind }_{m}+\Sigma b_{n} \text { Year }_{n}+\mu_{i t}
$$

where $C O N=U C_{-} P C A$ and $C C_{-} P C A$. Estimated residuals from this stage, $U C_{-} P C_{-} R$ and $C C_{-} P C A \_R$, are used in the later stage regressions.

The third-stage OLS model is:

$R l p m \_O C F_{i t}=\beta_{0}+\beta_{I} U C_{-} P C A_{-} R_{i t-1}$ *Shock $R_{i t-1}+\beta_{2} C C_{-} P C A_{-} R_{i t-1}$ *Shock $R_{i t-1}+\beta_{3} U C P C A_{-} R_{i t-1}+$

where Controls 5 are the same as in Model (7). 


\section{Table 9 Robustness Check for Relations between Unconditional and Conditional Conservatism and OCF Downside Risk}

This table reports estimation results for regressing alternative OCF downside risk on unconditional and conditional conservatism metrics and other control variables in Panel A, and for regressing Rlpm_OCF on alternative conditional conservatism measure $C C_{-} S k e w$ and $C C_{-} P C A A$ and other controls in Panel B. In particular, Models 1 to 6 use Rlpm_OCFind, Rlpm_OCFzero, Rlpm_OCFpre, Rlpm_OCF2, and Rlpm_OCF3 as alternative OCF downside risk measures. Model specifications and definitions of alternative OCF downside risk measures are provided at the bottom of the table, and other variable definitions are presented at the bottom of Table 1.

\begin{tabular}{|c|c|c|c|c|c|}
\hline \multicolumn{6}{|c|}{ Panel A: Alternative OCF Expectation Model for RLPM-based OCF Downside Risk Measures } \\
\hline \multirow[b]{2}{*}{ Variables } & \multicolumn{5}{|c|}{ Fama MacBeth Regression Models for Alternative OCF Downside Risk Measures } \\
\hline & $\begin{array}{c}\text { Model 1: } \\
\text { Rlpm_OCFind }\end{array}$ & $\begin{array}{c}\text { Model 2: } \\
\text { Rlpm_OCFzero }\end{array}$ & $\begin{array}{c}\text { Model 3: } \\
\text { Rlpm_OCFpre }\end{array}$ & $\begin{array}{c}\text { Model 5: } \\
\text { Rlpm_OCF2 }\end{array}$ & $\begin{array}{c}\text { Model 6: } \\
\text { Rlpm_OCF3 }\end{array}$ \\
\hline \multirow[t]{2}{*}{ Intercept } & 0.8882 & 0.8374 & 0.5892 & 0.5994 & 0.5299 \\
\hline & $(56.48)^{* * *}$ & $(47.3)^{* * *}$ & $(14.28)^{* * *}$ & $(26.8)^{* * *}$ & $(24.28)^{* * *}$ \\
\hline \multirow[t]{2}{*}{$\boldsymbol{U} \boldsymbol{C}_{-} \boldsymbol{P C} \boldsymbol{A}_{i t-1}$} & -0.1643 & -0.1756 & -0.0677 & -0.0359 & -0.0811 \\
\hline & $(-17.99)^{* * *}$ & $(-22.97)^{* * *}$ & $(-5.14) * * *$ & $(-7.67)^{* * *}$ & $(-20.73)^{* * *}$ \\
\hline \multirow[t]{2}{*}{$C C_{-} P \boldsymbol{C} A_{i t-1}$} & -0.1771 & -0.1899 & -0.1693 & -0.1165 & -0.1136 \\
\hline & $(-52.49) * * *$ & $(-78.04)^{* * *}$ & $(-35.61)^{* * *}$ & $(-52.53) * * *$ & $(-47.73)^{* * * *}$ \\
\hline Other Controls & Yes & Yes & Yes & Yes & Yes \\
\hline obs & 22,456 & 22,456 & 22,456 & 30,337 & 30,337 \\
\hline$R-s q r$ & 0.5667 & 0.5449 & 0.1686 & 0.3725 & 0.3266 \\
\hline
\end{tabular}

Panel B: CC_Skew as Alternative Conditional Conservatism Measures

\begin{tabular}{|c|c|c|c|c|c|c|}
\hline \multirow[t]{2}{*}{ Variables } & \multicolumn{2}{|c|}{$\begin{array}{l}\text { Logit Model for Indicator of } \\
\text { OCF Downside Risk DOCF }\end{array}$} & \multicolumn{2}{|c|}{$\begin{array}{c}\text { Fama MacBeth Model for } \\
\text { Rlpm_OCF }\end{array}$} & \multicolumn{2}{|c|}{$\begin{array}{c}\text { Fama MacBeth Model for } \\
\text { OCF at Risk } \mathrm{CFaR}\end{array}$} \\
\hline & Model 1 & Model 2 & Model 1 & Model 2 & Model 1 & Model 2 \\
\hline $\begin{array}{l}\text { Intercept } \\
U C_{-} P C_{i t-1}\end{array}$ & $\begin{array}{l}0.8718 \\
(5.74)^{* * *} \\
\mathbf{- 0 . 4 5 6 8} \\
(-\mathbf{4 . 9 2})^{* * *}\end{array}$ & $\begin{array}{l}0.9115 \\
(5.94)^{* * *} \\
\mathbf{- 0 . 4 8 7 4} \\
(\mathbf{- 5 . 2 6 )} * * *\end{array}$ & $\begin{array}{l}0.7594 \\
(37.80)^{* * *} \\
-0.0070 \\
(-0.85)\end{array}$ & $\begin{array}{l}0.7546 \\
(36.86)^{* * *} \\
\mathbf{- 0 . 0 1 4 9} \\
(\mathbf{- 1 . 7 6 ) *}\end{array}$ & $\begin{array}{l}0.8303 \\
(10.89)^{* * *} \\
\mathbf{- 0 . 1 0 3 6} \\
(\mathbf{- 1 5 . 9 8 )})^{* * *}\end{array}$ & $\begin{array}{l}0.8181 \\
(10.37)^{* * *} \\
\mathbf{- 0 . 1 0 1 4} \\
(\mathbf{- 1 7 . 3 4})^{* * *}\end{array}$ \\
\hline $\begin{array}{l}C C_{-} \boldsymbol{P C A} A_{i t-1} \\
\text { CC_Skew } w_{i t-1}\end{array}$ & $\begin{array}{l}-0.0770 \\
(-1.36)\end{array}$ & $\begin{array}{l}0.0271 \\
(0.44)\end{array}$ & $\begin{array}{l}-0.0779 \\
(-5.89) * * *\end{array}$ & $\begin{array}{l}-0.0677 \\
(-3.66)^{* * *}\end{array}$ & $\begin{array}{l}-0.0783 \\
(-7.36) * * *\end{array}$ & $\begin{array}{l}-0.1261 \\
(-4.66)^{* * *}\end{array}$ \\
\hline Other Controls & Yes & Yes & Yes & Yes & Yes & Yes \\
\hline $\begin{array}{l}\text { obs } \\
\text { Psuedo R-sqr } \\
\text { R-sqr }\end{array}$ & $\begin{array}{l}28,425 \\
0.4857\end{array}$ & $\begin{array}{l}28,425 \\
0.4857\end{array}$ & $\begin{array}{l}28,425 \\
0.7955 \\
\end{array}$ & $\begin{array}{l}28,425 \\
0.7924 \\
\end{array}$ & $\begin{array}{l}24,554 \\
0.4258 \\
\end{array}$ & $\begin{array}{l}24,554 \\
0.4271 \\
\end{array}$ \\
\hline
\end{tabular}

$*, * *$, and $* * *$ indicate a coefficient is significant at $90 \%, 95 \%$, and $99 \%$ confidence level, respectively.

The model used in this table is: $D R_{i t}=\alpha+\gamma C O N_{i t-1}+$ Controls $_{i t-1}+\mu_{i t-1}$ where $D R_{i t}=D R \_O C F i n d, D R \_O C F p r e, D R \_O C F z e r o, R l p m \_O C F 2_{i t}, R l p m \_O C F 3_{i t}$, and $R l p m \_O C F_{i t} . C O N=U C \_P C A$, $C C \_P C A, C C \_P C \bar{A} A, C C$ SKEW. Controls include Cash, $\triangle$ Cash, Invest_CAPX, Invest_RD, Leverage, Loss, OO, ROA, Sigma, Size, Slack, Slack_emp, CEO_Delta, CEO_Vega, Ind and Year dummies. DR_OCFind, DR_OCFpre, DR_OCFzero refer to the RRLPMs of OCF recalculated by replacing the OCF expectation model in equation (5) with previous year industry OCF mean, previous five-year mean of firm-specific OCF, and zero OCF. We define Rlpm_OCF2 as the natural logarithm of one plus the RLPM of OCF without deflating by the RUPM of OCF, and define Rlpm_OCF $\overline{3}$ as the natural logarithm of one plus the RLPM of OCF alternatively deflated by the standard deviation of OCF calculated over a horizon of three to five years. 